DIVISION OF THE HUMANITIES AND SOCIAL SCIENCES

CALIFORNIA INSTITUTE OF TECHNOLOGY

PASADENA, CALIFORNIA 91125

PRICE CONTROLS, NON-PRICE QUALITY COMPETITION, AND THE NONEXISTENCE OF COMPETITIVE EQUILIBRIUM

John William Hatfield

Stanford

Charles R. Plott

California Institute of Technology

Tomomi Tanaka

Arizona State University

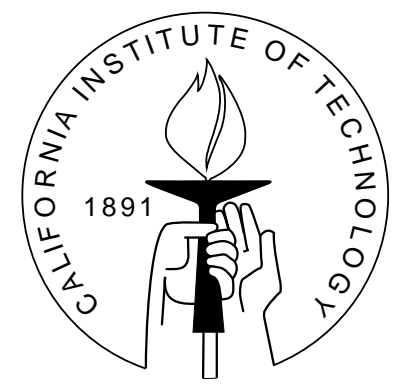

SOCIAL SCIENCE WORKING PAPER 1360

February 2012 


\title{
Price Controls, Non-Price Quality Competition, and the Nonexistence of Competitive Equilibrium
}

\author{
John William Hatfield \\ Graduate School of Business \\ Stanford University \\ Charles R. Plott* \\ Division of the Humanities and Social Sciences \\ California Institute of Technology \\ Tomomi Tanaka \\ School of Politics and Global Studies \\ Arizona State University
}

February 27, 2012

\begin{abstract}
We investigate how price ceilings and floors affect outomces in continuous time, double auction markets with discrete goods and multiple qualities. Since competitive equilibria need not exist in markets with price contols, we investigated the nature of non-price competition and how markets might evolve in its presence. We develop a quality competition model based on matching theory. Equilibria always exist in such price-constrained markets; moreover, they naturally correspond to competitive equilibria when competitive equilibria exist. Additionally, we characterize the set of equilibria in the presence of price restrictions. In a series of experiments, we find that market outcomes closely conform to the predictions of the model. In particular, price controls induce non-price competition between agents both in theory and in the experimental environment; market behaviors result in allocations close to the predictions of the model.
\end{abstract}

JEL Classification: C78, C92, C71

Keywords: Matching; Stability; Competitive Equilibrium; Core; Price Controls

*We are grateful to Marcus Berliant, Clayton Featherstone, Scott Duke Kominers, Muriel Niederle, Alvin E. Roth, Nilanjan Roy, William Zame and seminar participants at Boston College, the 2009 Lee Center Workshop at Caltech, Harvard Business School, and New York University for helpful discussions. We are also grateful to Matthew Jones who helped us conduct the experiments and to Hsing Yang Lee and Travis Maron for their technical assistance. The financial support of the Gordon and Betty Moore Foundation and the support of the Caltech Laboratory of Experimental Economics and Political Science are gratefully acknowledged. Hatfield appreciates the hospitality of Harvard Business School, and Tanaka appreciates the hospitality of University of Tokyo, which hosted them during parts of this research. Any comments or suggestions are welcome and may be emailed to cplott@hss.caltech.edu. 


\section{Introduction}

We investigate how price ceilings and floors affect outcomes in continuous time, double auction markets in which both price and quality can vary. Price controls are a pervasive form of government regulation: rent control, the minimum wage, and price supports for agricultural commodities are all common instances. Alterations in product quality have been suggested as an equilibrium response to the inability of the market to adjust supply and demand by price changes. ${ }^{1}$ Indeed, a number of works support the possibility that price controls induce quality competition in various regulated industries ${ }^{2}$, and other research investigates how job characteristics such as the amount of employer-supplied training are affected by the minimum wage. ${ }^{3}$ However, theoretical inquiry into this phenomenon has been frustrated by the fact that competitive equilibria may fail to exist when price controls are imposed. ${ }^{4}$

Due to this lack of a theoretical foundation, we conducted exploratory experiments of multi-quality markets where price controls were imposed. Two sets of experiments were conducted. Series 1 was designed to test the intuition that, when no price floors were imposed, agents would trade goods at the quality that maximized joint surplus, and when a price floor was imposed, agents would trade higher (and more expensive) quality goods for which joint surplus was lower.

Figure 1 illustrates the substance of Series 1 experiments, in which agents were placed in a market environment where buyers and sellers may transact at any of ten qualities,

\footnotetext{
${ }^{1}$ Such an effect has been suggested by Feldstein (1973), Leffler (1982), and Hashimoto (1982), among others.

${ }^{2}$ See Plott (1965) for an analysis of non-price competition by regulated dry cleaners, Douglas and Miller III (1974) for an analysis of non-price competition by airlines, and Joskow (1980) for an analysis of non-price competition by hospitals.

${ }^{3}$ See Hashimoto (1982) and Neumark and Wascher (2001).

${ }^{4}$ In general equilibrium theory, work by Dréze (1975) and van der Laan (1980) showed the existence of $l$-equilibria for markets with price restrictions by showing that there exists a set of $a d$ hoc supply/demand constraints on agents such that, given these constraints, there exists equilibrium prices. However, for markets with indivisible goods (such as those considered in this work), competitive equilibria are only guaranteed to exist when agents' preferences satisfy the gross substitutes condition; see Gul and Stacchetti (1999). However, even when preferences satisfy the gross substitutes condition, the existence of a competitive equilibrium can not be guaranteed when price controls are imposed.
} 


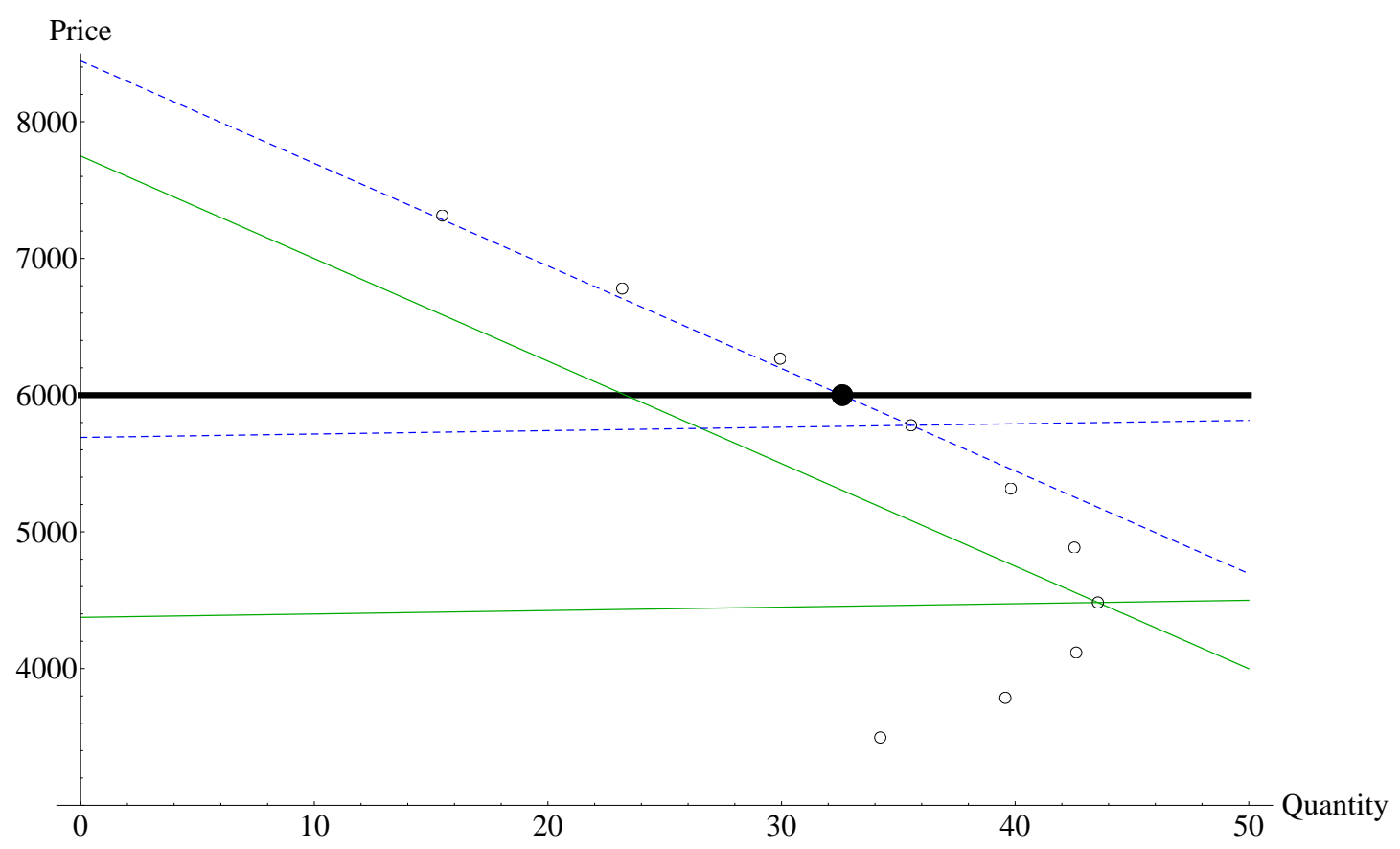

Figure 1: Illustration of an experimental market with ten vertically differentiated qualities $A, \ldots, J$. The thin green lines represent the demand and supply curves for the efficient quality $D$; the thin blue dashed lines represent the demand and supply curves for the inefficiently high quality $G$. Each circle denotes an equilibrium price and quantity if only one quality was available - for example, the point $(34,3496)$ represents the equilibrium when only the lowest quality, $A$, is available. The thick black line represents a price floor of 6000 - when such a price a price floor is imposed, in any stable outcome all trade takes place at a price of 6000 at quality $G$; this is represented by the disc at the intersection of the price floor and the demand curve for quality $G$ goods.

denoted $A, B, \ldots, J$, where $A$ is the lowest quality and $J$ is the highest quality. The utility a buyer recieves from a good is increasing in the quality of that good; however, the additional utility a buyer recieves from an incremental increase in quality is decreasing in initial quality. Analogously, the cost a sellers incurs from producing a good is increasing in the quality of that good, and moreover the additional cost a seller incurs from an incremental increase in quality is increasing in initial quality. Quality $D$ is the quality which maximizes joint surplus, and hence is the only quality traded in competitive equilibrium in an economy without price controls. The markets in Series 1 were unconstrained for some experiments; later, a price floor of 6000 was implemented. When this price floor exists, as illustrated by Figure 1, there is no feasible price for which demand equals supply in this market. Qualities with 
equilibrium prices above the floor (i.e., $G$ and all lower qualities) have an excess supply at the price floor, and qualities with equilibrium prices above the floor have an excess demand at the price floor. However, even though competitive equilibria do not exist, sellers can compete by offering higher quality at reduced prices.

In particular, we found in the Series 1 experiments that quality does respond to price controls and does so exactly in the manner suggested by economic intuition. Without price controls, the prices and qualities found in the market are close to the predictions derived from the competitive equilibrium: agents trade the unique efficient quality and the number of trades maximizes total surplus. ${ }^{5}$ By contrast, price floors above the competitive equilibrium price induce agents to trade higher quality goods; furthermore, overall market efficiency is lowered by the existence of a price floor.

A close examination of the data from Series 1 revealed that the experimental outcomes observed were well described by the $f$-core of a cooperative game with a continuum of unitdemand buyers and unit-supply sellers. ${ }^{6,7}$ This was despite the fact that in the experimental setting subjects had multi-unit demand/supply (and, furthermore, there was a small, finite number of subjects). In order to explore the reliability of this model, a second series of experiments was performed. In Series 2, a double auction market with three possible qualities was created, in which price floors and price ceilings were strategically placed to create different equilibria in the model under conditions for which competitive equilibria do not exist.

Close examination of the data from Series 2 indicated that the appropriate solution concept for predicting behavior in the presence of price controls is the notion of stability from matching theory. That discovery compelled us to consider stability as a solution concept

\footnotetext{
${ }^{5}$ The strong convergance properties of double auction markets to competitive equilibria are well-known: see Plott (1982) or Holt (1995) for an overview, as well as more recent work by Kirchsteiger et al. (2005) and Crockett et al. (2011).

${ }^{6}$ The $f$-core is a collection of finite coalitions such that no other finite coalition can provide all members of it with a higher payoff: see Kaneko and Wooders $(1986,1996)$ and Hammond et al. (1989).

${ }^{7}$ See Plott et al. (2007) for further details on this construction. The theoretical requirement of Plott et al. (2007) that there be a continuum of agents was relaxed by Hatfield et al. (2012); however, the model of Hatfield et al. (2012) still requires that each agent have unit-demand/supply.
} 
for environments with price controls in general and to our experimental environment in particular. In particular, we develop a two-sided model of exchange with a finite number of multi-unit demand buyers and multi-unit supply sellers, multiple qualities, and price controls; we show that stable outcomes exist in our setting. The foundation of our model relies heavily on Hatfield et al. (2011), who recently demonstrated that a natural correspondence exists between the set of stable outcomes and the set of competitive equilibria (in settings without price controls). ${ }^{8}$ We extend that analysis here to show that stable outcomes always exist in our setting, even when price restrictions are present, using techniques developed by Hatfield and Milgrom (2005), Echenique and Oviedo (2006), and Hatfield and Kominers (2011, 2012). In other words, stability is a natural generalization of competitive equilibrium, but stable outcomes exist even when competitive equilibria do not due to price controls.

A stable outcome is simply a set of transactions that is individually rational and unblocked: that is, there does not exist a transaction between a buyer and a seller that both would choose to engage in (possibly no longer executing other transactions they are a party to). Suppose there is one unit-demand buyer who values a good at 3, and two unit-supply sellers whose cost for producing the good is 1 . In that case, the competitive equilibrium and the stable outcome involve one of the sellers trading his good to the buyer at a price of 1 . If, however, a price floor of 2 is imposed, then no competitive equilibrium exists-both sellers demand to sell the good at the price of 2. However, there exist two stable outcomes: in each, one of the two sellers sells his good at a price of 2 to the buyer, and the other seller is unable to block this transaction, as any trade must have a price of 2 or greater. Stability is related to, but not the same as, the core: In our setting, stability provides a sharper prediction, as the set of stable outcomes is a strict subset of the core. ${ }^{9}$ In our first series of experiments, all trade takes place at the price floor for quality $G$ goods in any stable outcome; this is depicted in Figure 1, where the stable outcome is denoted with a disc at the intersection of

\footnotetext{
${ }^{8}$ See also the work by Sotomayor $(2007,2009)$ and Jaume et al. (2009), who demonstrate a similar correspondence in two-sided settings with discrete contracts (but without price controls).

${ }^{9}$ See Hatfield et al. (2011) for further discussion of the relationship between these two solution concepts.
} 
the price floor and the demand curve for quality $G$ goods.

The discovery of an explanatory theory allowed us to make specific, nontrivial, predictions regarding experimental outcomes and hence to directly examine the reliability of the model. The model predicts that for price floors slightly above the competitive equilibrium price (for the efficient quality), agents either trade the efficient quality at the price floor, or trade a good of quality one increment higher at a price reflecting exactly the increase in a buyer's utility from the quality difference. However, as the price floor is raised, eventually all trade will happen at the higher quality, and such trades of the higher quality good will be at a price strictly above the price floor. Analogous theoretical results are obtained for price ceilings.

The outcomes observed are very close to those predicted by the theory. ${ }^{10}$ In particular, for price floors slightly above the competitive equilibrium price, agents trade both the efficient quality at the price floor and a higher quality in accord with the predictions of the theory. Furthermore, the efficiency of the overall market falls within the interval predicted by the theory. When the price floor is raised to a level where theory predicts that only the high quality good is traded, almost all trade amongst the experimental subjects takes place at that quality, and does so at the price suggested by the theory; the efficiency of the overall market was within $8 \%$ of the predicted value. Experiments were also performed with price ceilings with very similar results.

The remainder of this paper is organized as follows. Section 2 introduces the model and characterizes the set of competitive equilibria and the set of stable outcomes. Section 3 describes the experimental procedure and parameters, and Section 4 then uses these parameters and the theory to make specific predictions of equilibrium behavior. Section 5 then compares these predictions to the experimental results. We conclude in Section 6. All proofs are in Appendix A.

\footnotetext{
${ }^{10}$ Our theory also makes accurate predictions for the equilibrium behavior of experimental subjects in Isaac and Plott (1981), which considers buyer-seller markets with price controls (but only one quality).
} 


\section{$2 \quad$ The Quality Competition Model}

\section{$2.1 \quad$ Framework}

There is a finite set of buyers $B$ and a finite set of sellers $S$. Any given buyer and seller can make a trade $\omega$ that denotes a buyer $\mathrm{b}(\omega) \in B$, a seller $\mathrm{s}(\omega) \in S$, and a quality $\mathrm{q}(\omega) \in Q$, where $Q$ is defined as a set of consecutive integers $\left\{q^{\min }, \ldots, q^{\max }\right\}$. If one seller sells multiple units of the same quality good to a buyer, this relationship will be represented by multiple trades. The finite set of trades is given by $\Omega$. For a given set of trades $\Psi \subseteq \Omega$, let $\Psi_{b}$ be the set of trades in $\Psi$ associated with buyer $b$, i.e., $\Psi_{b} \equiv\{\omega \in \Omega: \mathrm{b}(\omega)=b\}$, and similarly let $\Psi_{s} \equiv\{\omega \in \Omega: \mathrm{s}(\omega)=s\}$.

We can define transactions in terms of contracts. A contract $\left(\omega, p_{\omega}\right)$ is a trade along with an associated transfer price; the set of contracts is given by $X \equiv \Omega \times \mathbb{R}$. For a contract $x=\left(\omega, p_{\omega}\right)$, we let $\mathrm{b}(x) \equiv \mathrm{b}(\omega), \mathrm{s}(x) \equiv \mathrm{s}(\omega), \mathrm{q}(x) \equiv \mathrm{q}(\omega)$, and $\mathrm{p}(x) \equiv p_{\omega}$. We also define $\mathrm{b}(Y) \equiv \bigcup_{x \in Y} \mathrm{~b}(x)$ and $\mathrm{s}(Y) \equiv \bigcup_{x \in Y} \mathrm{~s}(x)$. Finally, we let $Y_{b}$ be the set of contracts in $Y$ associated with buyer $b$, i.e., $Y_{b} \equiv\{x \in X: \mathrm{b}(x)=b\}$, and similarly let $Y_{s} \equiv\{x \in Y: \mathrm{s}(x)=s\}$; we let the set of all agents associated with some contract in $Y$ be denoted as $\mathrm{a}(Y) \equiv \mathrm{b}(Y) \cup \mathrm{s}(Y)$.

We also define a price vector $p \in \mathbb{R}^{\Omega}$ which states a price $p_{\omega}$ for each $\omega \in \Omega$. An arrangement $[\Psi ; p]$ is a set of trades $\Psi \subseteq \Omega$ and a price vector $p \in \mathbb{R}^{\Omega}$.

A set of contracts $Y \subseteq X$ is an outcome if it is feasible, that is no two contracts refer to the same trade: if $\left(\omega, p_{\omega}\right),\left(\omega, \tilde{p}_{\omega}\right) \in Y$, then $\left(\omega, p_{\omega}\right)=\left(\omega, \tilde{p}_{\omega}\right)$. Note that in contrast to arrangements, an outcome $Y$ only describes prices for those trades that are part of contracts in $Y$. Let

$$
\tau(Y) \equiv\left\{\omega \in \Omega:\left(\omega, p_{\omega}\right) \in Y \text { for some } p_{\omega} \in \mathbb{R}\right\}
$$

the set of trades associated with contracts in $Y$. For an arrangement $[\Psi ; p]$, let

$$
\kappa([\Psi ; p]) \equiv\left\{\left(\omega, \tilde{p}_{\omega}\right) \in X: \omega \in \Omega \text { and } \tilde{p}_{\omega}=p_{\omega}\right\}
$$

be the set of contracts that execute the trades $\Psi$ at prices $p$ in the arrangement $[\Psi ; p]$. 


\subsubsection{Preferences}

The valuation function $u^{b}$ of buyer $b \in B$ for a set of trades $\Psi \subseteq \Omega$ is given by

$$
u^{b}(\Psi) \equiv f^{b}\left(\left|\Psi_{b}\right|\right)+\sum_{\omega \in \Psi_{b}} v(\mathbf{q}(\omega))
$$

where $f^{b}(n)$ is the value $b$ obtains from procuring $n$ goods and $v(q)$ is the additional utility $b$ obtains from procuring a good of quality $q$. Let $f^{b}$ be strictly increasing and concave, and let $v$ be strictly concave.

The valuation function of seller $s \in S$ for a set of trades $\Psi \subseteq \Omega$ is given by

$$
u^{s}(\Psi) \equiv-c^{s}\left(\left|\Psi_{s}\right|\right)-\sum_{\omega \in \Psi_{s}} e(\mathbf{q}(\omega))
$$

where $c^{s}$ is the cost $s$ incurs from producing $n$ goods and $e(q)$ is the additional cost $s$ incurs from producing a good of quality $q$. Let $c^{s}$ be strictly increasing and convex, and let $e$ be strictly convex. ${ }^{11}$

For ease of exposition, we assume that there is a unique quality $\hat{q}$ that maximizes surplus, i.e.,

$$
\{\hat{q}\} \equiv \underset{q \in Q}{\arg \max } v(q)+e(q)
$$

and furthermore that $\hat{q}$ is neither the highest nor lowest quality, i.e., $q^{\min }<\hat{q}<q^{\max }$.

The utility functions of a buyer $b \in B$ and a seller $s \in S$ for an outcome $Y \subseteq X$ are given by

$$
\begin{aligned}
U^{b}(Y) & \equiv u^{b}(\tau(Y))-\sum_{y \in Y} \mathrm{p}(y), \\
U^{s}(Y) & \equiv u^{s}(\tau(Y))+\sum_{y \in Y} \mathrm{p}(y) .
\end{aligned}
$$

For an arrangement $[\Psi ; p]$, we let $U^{i}([\Psi ; p]) \equiv U^{i}(\kappa([\Psi ; p]))$ for all $i \in B \cup S$.

\footnotetext{
${ }^{11}$ This characterization of buyer and seller's utility functions is equivalent to the cardinality condition of Bevia et al. (1999). These assumptions on preferences and agents are more restrictive assumptions than is necessary for some of our results; however, these assumptions closely parallel our experimental design. For a more general model (without price restrictions), see Hatfield et al. (2011).
} 
Using these utility functions we define the demand correspondence for $i \in B \cup S$ given a price vector $p \in \mathbb{R}^{|\Omega|}$ as

$$
D^{i}(p) \equiv \underset{\Psi \subseteq \Omega_{i}}{\arg \max } U^{i}([\Psi ; p]) .
$$

Similarly, we define the choice correspondence from a finite set of contracts $Y \subseteq X$ as

$$
C^{i}(Y) \equiv \underset{Z \subseteq Y_{i}}{\arg \max } U^{i}(Z)
$$

\subsubsection{Definition of Equilibrium}

We now define two distinct notions of equilibrium, competitive equilibrium and stability.

Definition. A competitive equilibrium is an arrangement $[\Psi ; p]$ such that

$$
\Psi_{i} \in D^{i}(p)
$$

for all $i \in B \cup S$.

This definition encodes both individual optimization (as each agent demands an optimal set of trades, given prices) and market clearing (as a buyer demands an object from a seller at a given price if and only if the seller is willing to sell him that item).

We now define stability:

Definition. An outcome $A \subseteq X$ is stable if it is

1. Individually rational: for all $i \in B \cup S, A \in C^{i}(A)$.

2. Unblocked: there does not exist a nonempty blocking set $Z \subseteq X$ such that

(a) $Z \cap A=\varnothing$, and

(b) for all $i \in \mathrm{a}(Z)$, we have that $Z_{i} \subseteq Y^{i}$ for all $Y^{i} \in C^{i}(Z \cup A)$.

The first condition, individual rationality, states that no agent is strictly better off by choosing a strict subset of his contracts in $A$. The second condition states that there does not exist a set of contracts $Z$ such that all the agents involved in $Z$ would strictly prefer to 
sign all of them (and possibly drop some of their existing contracts in $A$ ) to sticking with their contracts in $A$.

Note that a blocking set may be of any size and involve an arbitrary number of agents. However, in the context of our quality competition model, for any blocking set $Z$, the set $\{z\} \subseteq Z$ is also a blocking set. In other words, for any blocking set, any contract within that blocking set is a blocking set in and of itself. Hence, while an outcome is stable only if there does not exist a blocking set, for any outcome that is not stable, the outcome is either not individually rational or there exists a blocking set containing one contract.

The notion of stability is also closely related to the core, defined below:

Definition. An outcome $A$ is in the core if it is core unblocked, i.e., there does not exist a set of contracts $Z$ such that, for all $i \in \mathrm{a}(Z), U^{i}(Z)>U^{i}(A)$.

An outcome is in the core if there does not exist a set of agents who, by dropping all of their current contracts and signing contracts only amongst themselves can make each of them strictly better off. The definition of the core differs from the definition of stability in two ways. First, a core block requires that all agents who are associated with the blocking set drop all of their contracts with agents not associated with the blocking set; this is a more stringent restriction than that imposed by stability, where agents associated with the blocking set may retain previously held contracts. Second, a core block does not require that $Z_{i} \in C^{i}(Z \cup A)$ for all $i \in \mathrm{a}(Z)$; rather, it requires the less stringent condition that $U^{i}(Z)>U^{i}(A)$ for all $i \in \mathrm{a}(Z)$.

However, when preferences are substitutable, as is the case here, the set of competitive equilibria, the set of stable outcomes, and the core are all closely related.

Theorem 1. For any competitive equilibrium $[\Psi ; p], \kappa([\Psi ; p])$ is a stable outcome; furthermore, any stable outcome is in the core. Conversely, for any core outcome A, there exists a stable outcome $\hat{A}$ such that $\tau(A)=\tau(\hat{A})$.

This theorem shows that when competitive equilibria exist, they induce stable outcomes. 
In fact, when no price restrictions are present, a converse result holds as well: all stable outcomes induce competitive equilibria. ${ }^{12}$ However, when price restrictions are present, competitive equilibria may not exist, and so stable outcomes do not, in general, induce competitive equilibria.

While the core is a natural solution concept in this setting, it does not make specific predictions about prices, as if a buyer and seller may engage in multiple trades with each other, those trades can be at prices that are not supportable in a stable outcome or competitive equilibrium. Furthermore, the set of realizable utility outcomes is strictly larger for the set of core outcomes than for the set of stable outcomes. For instance, suppose there is only one buyer $b$, one seller $s$, a set of trades $\Omega=\{\psi, \omega\}$, and let

$$
\begin{aligned}
& u^{b}(\Psi)=4|\Psi| \\
& u^{s}(\Psi)=-3 \max \{0,|\Psi|-1\}
\end{aligned}
$$

the buyer has constant marginal utility from each item, while the seller only incurs a cost if he sells both items. Then $\{(\psi, 2),(\omega, 2)\}$ is a core outcome, but it is not stable (and does not induce a competitive equilibrium). In particular, the seller will obtain a utility of at least 3 in any stable outcome, but only receives a utility of only 1 in this core outcome. ${ }^{13}$

\subsection{Characterization of Equilibrium}

Before we fully characterize the set of stable outcomes, it will be helpful to consider the case where there are no price restrictions and the set of trades is restricted to one quality. Let $\Omega(\bar{q}) \equiv\{\omega \in \Omega: \mathbf{q}(\omega)=\bar{q}\}$ and let $X(\bar{q}) \equiv \Omega(\bar{q}) \times \mathbb{R}$.

\footnotetext{
${ }^{12}$ Formally, when we say that stable outcome induces a competitive equilibrium, we mean that for a stable outcome $A$, there exists a price vector $\tilde{p} \in \mathbb{R}^{\Omega}$ such that $[\tau(A) ; \tilde{p}]$ is a competitive equilibrium such that if $\left(\omega, p_{\omega}\right) \in A$, then $\tilde{p}_{\omega}=p_{\omega}$. See Hatfield et al. (2011) for a proof and discussion of this result.

${ }^{13}$ Note that this phenomenon is only present if both buyers and sellers may demand multiple contracts. If agents on one side of the market demand at most one contract, then the core and the set of stable outcomes coincide; see Hatfield and Milgrom (2005). Furthermore, this phenomenon is present only when there are a finite number of buyers and sellers or indivisible goods; for economies with a continuum of agents and divisible goods, the set of competitive equilibria allocations again coincides with the core; see Hammond et al. (1989).
} 
Theorem 2. Suppose there are no price restrictions, and the set of contracts is given by $X(\bar{q})$. Then a stable outcome exists, and for any stable outcome A:

1. The number of contracts $|A|$ is an element of

$$
\underset{n \in \mathbb{Z}_{\geq 0}}{\arg \max _{b \in B}}\left\{\sum_{b \in}\left[f\left(n_{b}\right)+v(\bar{q})\right]-\sum_{s \in S}\left[c\left(n_{s}\right)+e(\bar{q})\right]\right\}
$$

where

$$
\sum_{b \in B} n_{b}=\sum_{s \in S} n_{s}=n .
$$

2. For all $\left(\omega, p_{\omega}\right) \in A, p_{\omega} \in\left[p^{\min }(\bar{q}), p^{\max }(\bar{q})\right]$, where

$$
\begin{aligned}
p^{\min }(\bar{q}) & \equiv \max _{b \in B, s \in S}\left\{f^{b}\left(\left|A_{b}\right|+1\right)-f^{b}\left(\left|A_{b}\right|\right)+v(\bar{q}), c^{s}\left(\left|A_{s}\right|\right)-c^{s}\left(\left|A_{s}\right|-1\right)+e(\bar{q})\right\} \\
p^{\max }(\bar{q}) & \equiv \min _{b \in B, s \in S}\left\{f^{b}\left(\left|A_{b}\right|\right)-f^{b}\left(\left|A_{b}\right|-1\right)+v(\bar{q}), c^{s}\left(\left|A_{s}\right|+1\right)-c^{s}\left(\left|A_{s}\right|\right)+e(\bar{q})\right\}
\end{aligned}
$$

The theorem makes two specific predictions about behavior when only one quality is available. First, the theorem predicts that a surplus-maximizing number of trades will take place. Second, the theorem predicts that all trades will take place at a price in the interval $\left[p^{\min }(\bar{q}), p^{\max }(\bar{q})\right]$. The lower bound of this interval is the minimal price such that no buyer wishes to buy one more unit and every seller wishes to sell his prescribed number of units. Conversely, the upper bound of this interval is the maximal price such that every buyer wishes to buy his prescribed number of units, and no seller wishes to sell one more unit.

\subsubsection{Without Price Restrictions}

When no price restrictions are present the set of stable outcomes is as in Theorem 2 where the one quality present is the efficient quality $\hat{q}$.

Theorem 3. Suppose there are no price restrictions. A stable outcome exists, and for any stable outcome A, $A$ is efficient and:

1. For all $\psi \in \tau(A), \mathbf{q}(\psi)=\hat{q}$. 
2. The number of contracts $|A|$ is an element of

$$
\underset{n \in \mathbb{Z}_{\geq 0}}{\arg \max }\left\{\sum_{b \in B}\left[f\left(n_{b}\right)+v(\hat{q})\right]-\sum_{s \in S}\left[c\left(n_{s}\right)+e(\hat{q})\right]\right\}
$$

where

$$
\sum_{b \in B} n_{b}=\sum_{s \in S} n_{s}=n .
$$

3. For all $\left(\omega, p_{\omega}\right) \in A, p_{\omega} \in\left[p^{\min }(\hat{q}), p^{\max }(\hat{q})\right]$

The theorem makes three specific predictions. First, the theorem predicts that all trade will take place at the efficient quality $\hat{q}$. Second, the theorem predicts that a surplusmaximizing number of trades will take place, given that quality. Finally, the theorem predicts that all trades will take place at prices in the interval $\left[p^{\min }(\hat{q}), p^{\max }(\hat{q})\right]$ : The lower bound is high enough such that no buyer wishes to buy an additional item, and every seller receives nonnegative surplus from each item he sells, and, conversely, the higher bound is low enough such that every buyer receives nonnegative surplus from each item he buys, and no seller wishes to sell an additional item.

\subsubsection{With Price Restrictions}

We now consider the case where there is a price floor $p_{f}$. In characterizing the set of stable outcomes, there are essentially three cases to consider, as exemplified in Figure 2. The first is that the price floor does not bind, i.e., $p_{f}<p^{\min }(\hat{q})$. In this case, the price floor has no effect on the market, as the buyer and seller can always renegotiate to the efficient quality in a contract that makes both parties better off.

In the second case, the price floor is above $p^{\max }(q)$ for some $q \geq \hat{q}$, and below $p^{\min }(q+1)-$ $[v(q+1)-v(q)]$; this is the case where the price floor lies above the lower set of dashed lines but below the dotted lines in Figure 2. In that case, there may be trade at both the quality $q$ and $q+1$. The price of the higher quality good must be greater than the price of the lower quality good by exactly the difference in the buyers' valuation of the qualities; otherwise, a buyer who is worse off given the current prices and the quality he is trading at will offer a 


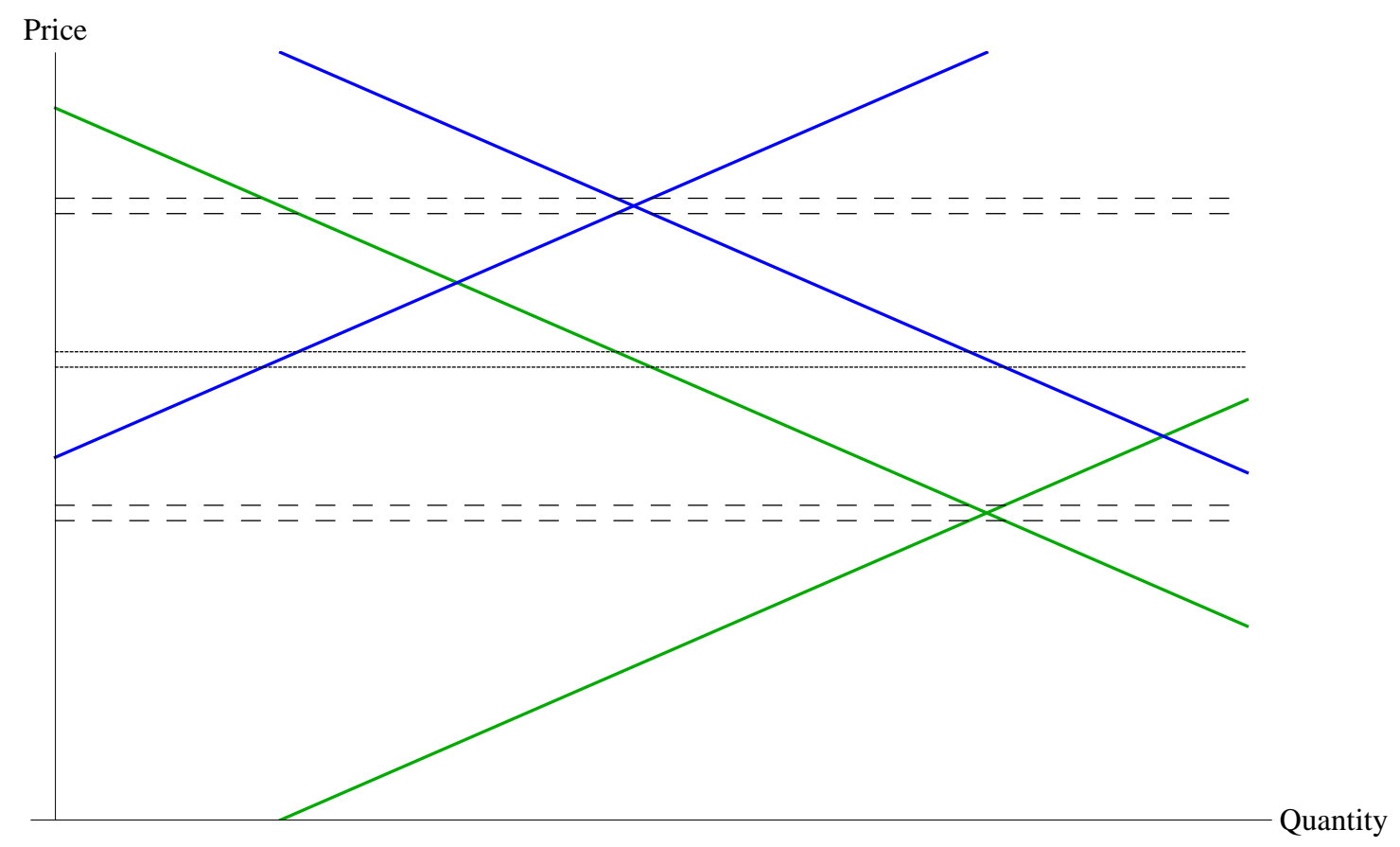

Figure 2: Illustration of the experimental market with two vertically differentiated qualities. The green lines represent the demand and supply curves for the efficient low quality; the blue lines represent the demand and supply curves for the inefficiently high quality. The dashed lines denote $p^{\min }(q)$ and $p^{\max }(q)$ for each quality $q$. The dotted black lines represent $p^{\min }(q+1)-[v(q+1)-v(q)]$ and $p^{\max }(q+1)-[v(q+1)-v(q)]$. When the price floor is below the lower set of dashed lines, Case 1 of Theorem 4 applies. When the price floor is above the lower set of dashed lines but below the dotted lines, Case 2 of Theorem 4 applies. Finally, when the price floor is above the dotted lines but below the higher set of dashed lines, Case 3 of Theorem 4 applies.

slightly higher price to a seller currently trading at the other quality. Furthermore, the lower price must be at the price floor, as otherwise sellers of the (inefficiently) high quality good would offer a buyer of the lower quality good the same good at a slightly lower price and gain the efficiency surplus. However, when the prices differ by this exact amount, and the lower quality good trades at the price floor, both qualites can trade in positive quantities as part of a stable outcome. In this stable outcome, none of the sellers who are not currently trading can make a positive profit by offering the higher quality good at a lower price, and these sellers also can not offer the lower quality good at a lower price, as it is trading at the price floor.

In the third case, the price floor is such that $p_{f}+[v(q+1)-v(q)]>p^{\max }(q+1)$ holds; this 
is the case where the price floor lies above the dotted lines in Figure 2. In this case, it will no longer be possible to sell the quality $q$ good, since there will be sellers without a current trading partner willing to trade the quality $q+1$ good at a price that makes it attractive to current buyers of the quality $q$ good. In that case, trade will be limited to only quality $q+1$ goods, so long as the price floor remains below $p^{\min }(q+1)$; hence, the stable outcome will be as if trade at only quality $q+1$ was available. Note that, in this case, the price floor $p_{f}$ affects the outcome even though no trade occurs at $p_{f}$.

We formalize this discussion below.

Theorem 4. Consider a price floor $p_{f}$. A stable outcome exists. There are three cases:

1. $p_{f}<p^{\min }(\hat{q})$ : Then any stable outcome is as in Theorem 3 .

2. $p^{\max }(q)<p_{f}<p^{\min }(q+1)-[v(q+1)-v(q)]$ for some $q \geq \hat{q}$ : Then in any stable outcome A,

(a) For any contract $x \in A$, we have that either

i. $\mathrm{q}(x)=q$ and $\mathrm{p}(x)=p_{f}$, or

ii. $\mathbf{q}(x)=q+1$, and $\mathrm{p}(x)=p_{f}+[v(q+1)-v(q)]$.

(b) The number of contracts $|A|$ is an element of

$$
\underset{n \in \mathbb{Z}_{\geq 0}}{\arg \max }\left\{\sum_{b \in B}\left[f^{b}\left(n_{b}\right)+v(q)-p_{f}\right]\right\}
$$

where

$$
\sum_{b \in B} n_{b}=n
$$

3. $p^{\max }(q+1)-[v(q+1)-v(q)]<p_{f}<p^{\min }(q+1)$ for some $q \geq \hat{q}$ : Then any stable outcome is as in Theorem 2 with quality $q+1$.

Imposing a price floor induces three separate forms of inefficiency. First, some agents may contract at an inefficient quality. Second, some agents may not contract at all, even though 
there exist surplus-increasing trades; for a contract to increase the welfare of both parties, it must have a price below the price floor. Finally, the wrong agents may contract - that is, in case 2 of Theorem 4, there may be sellers who would like to contract with a buyer at the price floor, and in fact have a lower marginal cost of production than a current seller; however, they can not undercut that current seller due to the price floor.

We now consider the case where there is a price ceiling, which is analogous to the case of a price floor, except that the roles of buyers and sellers are reversed.

Theorem 5. Consider a price ceiling $p_{c}$. A stable outcome exists. There are three cases:

1. $p_{c}>p^{\max }(\hat{q})$ : Then any stable outcome is as in Theorem 3 .

2. $p^{\min }(q)>p_{c}>p^{\max }(q-1)+[e(q)-e(q-1)]$ for some $q \leq \hat{q}$ : Then in any stable outcome $A$,

(a) For any contract $x \in A$, either

i. $\mathrm{q}(x)=q$ and $\mathrm{p}(x)=p_{c}$, or

ii. $\mathrm{q}(x)=q-1$ and $\mathrm{p}(x)=p_{c}-[e(q)-e(q-1)]$.

(b) The number of contracts $|A|$ is an element of

$$
\underset{n \in \mathbb{Z}_{\geq 0}}{\arg \max }\left\{\sum_{s \in S}\left[p_{c}-c\left(n_{b}\right)-e(q)\right]\right\}
$$

where

$$
\sum_{s \in S} n_{s}=n
$$

3. $p^{\min }(q-1)+[e(q)-e(q-1)]>p_{c}>p^{\max }(q-1)$ for some $q \leq \hat{q}$ : Then any stable outcome is as in Theorem 2 with quality $q-1$.

\section{$3 \quad$ Experimental Series and Markets}

The general structure of the experiments is contained in Table 1. A total of nine experiments were conducted. Each experiment consisted of 7-8 buyers and 7-8 sellers. Subjects 
were undergraduate students at the California Institute of Technology who had previous experience in participating in computerized double auction markets. Subjects were located in the Caltech Laboratory for Experimental Economics and Political Science and each experiment lasted about three hours. A subject was randomly assigned to be either a seller or a buyer upon arrival. Subjects were then given instructional sheets, record sheets, and payoff tables that described his or her own redemption values or costs.

All markets were conducted through Caltech's electronic market system, Marketscape. This program supports multiple markets through a double auction system with an open book. Goods of varying quality may be traded, and the order book for each good is visible to all of the participants. The best buy offers and the best sell offers in all markets are public on a single screen as are the prices of the last contracts accepted in each of the markets. The system operates in a sequence of periods. Each period is of fixed length and a countdown clock shows the number of seconds left in a period. Buyers are free to submit orders to buy at a price and quantity, which are entered into the book, where they remain until traded or cancelled. Similarly, sellers submit sell orders of a price and quantity, which are entered into the sell order book. A buyer sees a list of the sell orders listed from the lowest price to the highest for each quality market on his/her screen, and a seller sees a corresponding list of the buy offers listed from the highest price to the lowest for each quality market on his/her screen. These books are updated in real time as new orders are submitted. A trade takes place when a buyer or seller submits an order that "crosses" an offer of a counterparty.

When a period closes, a buyer's earnings for that period are the total value of all goods purchased minus the sum of the purchase prices. A seller's earnings are the sum of the prices for items he sold minus the costs of production.

Each period is independent: purchases and sales in a prior period have no effect on another period's payoffs. The subject has the opportunity to record and study profits for the period and the profitability of previous periods. The number of periods is unknown to the subjects. 
There were four types of buyers and four types of sellers in each session. The redemption values and costs differed across different types. The information of each individual was limited to information about his or her own payoff. They were not aware of the existence of different types or the costs, payoffs, or conversion rates of others. The instruction sheet can be found in Appendix B. The type of currency used in the experiments was francs. The conversion rate differed across subjects, depending on their types. Before each experiment started, a trial period was conducted to familiarize subjects with the procedure. Each individual maintained his or her own record of activities and earnings but the records were also maintained in the computer and were available to individual subjects at the end of each period. During a period the computer maintained a real time record of purchases and earnings, together with a time series of prices in each market.

\subsection{Experimental Markets}

There were two series of experimental markets. Series 1 is based on ten different qualities of the good, called $A, B, \ldots, J . A$ is the the lowest quality (i.e. the quality with the lowest value to the buyer and the lowest cost to produce for the seller), and $J$ is the highest quality. We conducted five sessions in Series 1. We did not impose any price controls for the first two sessions (1.1 and 1.2). In the last three sessions (1.3-5), we imposed a price floor of 6000, which is above $p^{\max }(G)$. In sessions 1.4 and 1.5, we removed the price floor in later periods to see if the market adjusts to the competitive equilibrium.

In Series 2, there are three qualities, $A, B$, and $C$ in the experimental market. We conducted four sessions for Series 2. In sessions 2.1 and 2.2, we imposed price floors of 1312 and 1470, respectively. These sessions correspond to the second and third cases of Theorem 4, respectively. In sessions 2.3 and 2.4, we imposed price ceilings of 1088 and 930, which correspond to the second and third cases of Theorem 5, respectively. In session 2.2, we

removed the price floor in the last 3 periods to see if the market adjusted to the competitive equilibrium. The experimental conditions are summarized in Table 1. 


\subsection{Preferences and Incentive Procedures}

\subsubsection{Series 1 (Ten Qualities)}

Buyers (sellers) were given tables stating their valuations (costs) of obtaining (producing) a good depending on the good's quality and how many goods had already been bought (sold) by that agent. Table 2 shows the values given to a Type 1 buyer. For a buyer $b$ of type $k$, where $k \in\{1,2,3,4\}$, the valuation function of $b$ is given by

$$
u^{b}(|\Psi|)=\left((6438-150 k)-300\left|\Psi_{b}\right|\right)\left|\Psi_{b}\right|+\sum_{\omega \in \Psi_{b}} v(q(\omega)),
$$

where the utility $v(q)$ obtained from a quality $q$ good is given by

$$
\begin{array}{lll}
v(A)=0, & v(B)=692 & v(C)=1250 \\
v(D)=1686 & v(E)=2012 & v(F)=2240 \\
v(G)=2382 & v(H)=2450 & v(I)=2456 \\
v(J)=2412 . & &
\end{array}
$$

Table 2 also shows the costs given to a Type 1 seller. For a seller $s$ of type $k$, where $k \in\{1,2,3,4\}$, the valuation function of $s$ is given by

$$
u^{s}(|\Psi|)=-\left((3398+5 k)+10\left|\Psi_{s}\right|\right)\left|\Psi_{s}\right|-\sum_{\omega \in \Psi_{s}} e(q(\omega)),
$$

where the disutility $e(q)$ from producing a quality $q$ good is given by

$$
\begin{array}{lll}
e(A)=0 & e(B)=277 & e(C)=600 \\
e(D)=964 & e(E)=1368 & e(F)=1807 \\
e(G)=2280 & e(H)=2782 & e(I)=3312 \\
e(J)=3865 . & &
\end{array}
$$

Notice the marginal utility from an additional unit depends only on the number of units the buyer (seller) has already consumed (produced), not on the characteristics or combination of units the buyer (seller) has already consumed (produced). This ensures that the marginal 
valuation of an additional unit is independent of the composition of the commodities the subject has already purchased or sold.

\subsubsection{Series 2 (Three Qualities)}

In Series 2, there were three qualities of goods, $A, B$, and $C$. Similar to Series 1 , subjects were given tables stating their valuations and costs. Table 3 shows the values given to a Type 1 buyer. For a buyer $b$ of type $k$, where $k \in\{1,2,3,4\}$, the valuation function of $b$ is given by

$$
u^{b}(|\Psi|)=\left((1690-45 k)-90\left|\Psi_{b}\right|\right)\left|\Psi_{b}\right|+\sum_{\omega \in \Psi_{b}} v(q(\omega))
$$

where the utility $v(q)$ obtained from a quality $q$ good is given by

$$
v(A)=0 \quad v(B)=600 \quad v(C)=800 .
$$

Note that, as in Series 1, the marginal utility of an additional good only depends on that good's quality and on the number of goods the agent has already bought, not the quality of the goods the agent has already bought.

Table 3 also shows the costs given to a Type 1 seller in Series 2. For a seller $s$ of type $k$, where $k \in\{1,2,3,4\}$, the valuation function of $s$ is given by

$$
u^{s}(|\Psi|)=-\left((-90+45 k)+90\left|\Psi_{s}\right|\right)\left|\Psi_{s}\right|-\sum_{\omega \in \Psi_{s}} e(q(\omega))
$$

where the cost $e(q)$ from producing a quality $q$ good is given by

$$
e(A)=0 \quad e(B)=200 \quad e(C)=800 .
$$

Note that, as in Series 1, the marginal disutility of an additional good only depends on that good's quality and on the number of goods the agent has already sold, not the quality of the goods the agent has already sold. 


\section{Predictions}

\subsection{Series 1 (Ten Qualities)}

Experiments based on Series 1 parameters had ten qualities, as described in the introduction and depicted in Figure 1. The quality $D$ is the most efficient. With no price controls, in any stable outcome (or competitive equilibrium) with 8 sellers and 8 buyers, 44 units of quality $D$ are traded at a price in the interval $[4482,4487] .{ }^{14}$ When there are 8 sellers and 8 buyers, total surplus from trade is 73458 in any stable outcome. ${ }^{15}$

For sessions $1.3-5$ a price floor of 6000 was imposed. The price interval for quality $G$ is $\left[p^{\min }(G), p^{\max }(G)\right]=[5778,5783]$; the price interval for quality $H$ is $\left[p^{\min }(H), p^{\max }(H)\right]=$ $[6265,6270]$. The marginal value to the buyer of an increase in quality from $G$ to $H$ is 68 . Hence the set of stable outcomes is characterized by case 2 of Theorem 4 . The theorem predicts that 32 units of either quality $G$ or $H$ will be traded, with the price of $G$ being 6000 and the price of $H$ being 6068. However, the minimum cost to produce good $H$ is 6195 , which is greater than 6068 , and so it is expected that all trade will be of quality $G$ goods at the price floor of 6000 ; this outcome is represented by the intersection of the price floor and the demand curve for quality $G$ goods in Figure $1 .{ }^{16}$ When there are 8 sellers and 8 buyers, total surplus from trade is 48464 in any stable outcome. ${ }^{17}$

\subsection{Series 2 (Three Qualities)}

Experiments based on Series 2 parameters had three qualities. The "middle" quality $B$ is the most efficient. With no price controls, in any stable outcome (or competitive equilibrium)

\footnotetext{
${ }^{14}$ In experiments 1.2 and 1.3 , we had 8 sellers and 7 buyers. In these experiments, 39 units of quality $D$ are traded at 4472 francs in any stable outcome. In experiment 1.5, we had 7 sellers and 7 buyers. In this experiment, 39 units of quality $D$ are traded at a price in the interval $[4482,4487]$ in any stable outcome.

${ }^{15}$ When there are 8 sellers and 7 buyers, total surplus is 65728 in any stable outcome. When there are 7 sellers and 7 buyers, total surplus is 65498 in any stable outcome.

${ }^{16}$ When there are 8 sellers and 7 buyers, as in experiment 1.3, 28 units of $G$ should be traded in any stable outcome. When there are 7 sellers and 7 buyers, as in experiment 1.5, 28 units of $G$ should be traded in any stable outcome.

${ }^{17}$ When there are 8 sellers and 7 buyers, as in experiment 1.3, total surplus is 43446 in any stable outcome. When there are 7 sellers and 7 buyers, as in experiment 1.5, total surplus is 43336 in any stable outcome.
} 
with 8 sellers and 8 buyers, 44 units of quality $B$ are traded at a price in the interval $[1190,1210]$. Total market surplus is 42460 in any stable outcome.

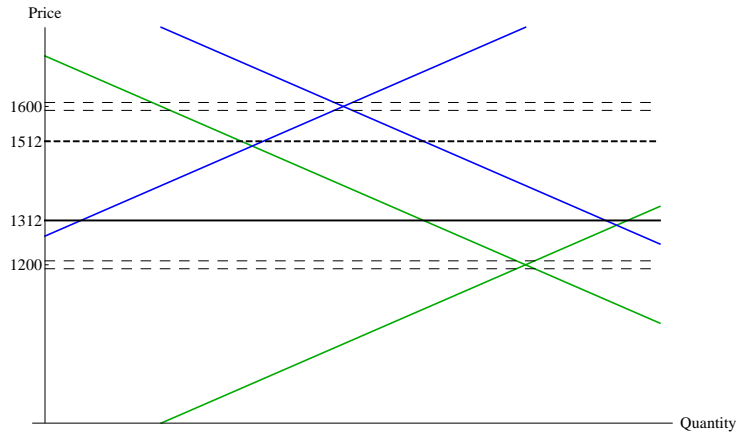

(a) $p_{f}=1312$.

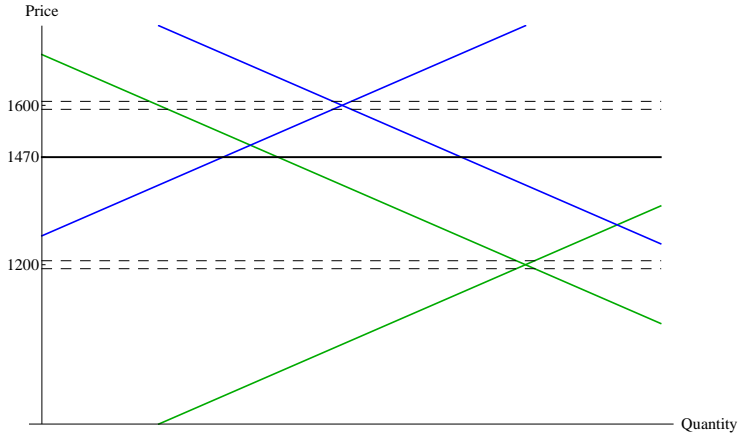

(b) $p_{f}=1470$.

Figure 3: In each subfigure, the green lines denote the supply and demand for the efficient quality $B$, while the blue lines denote the supply and demand for the inefficiently high quality $C$; the dashed lines at 1190 and 1210 denote $p^{\min }(B)$ and $p^{\max }(B)$, while the dashed lines at 1590 and 1610 denote $p^{\min }(C)$ and $p^{\max }(C)$. In Fig. 3(a), the black line at 1312 denotes the price floor at which quality $B$ goods trade, while the dashed line at 1512 denotes the price at which quality $C$ goods trade. In Fig. 3(b), the black line at 1470 denotes the price floor; in this case, only quality $C$ goods trade, and do so at a price in the interval $[1590,1610]$.

In session 2.1, a price floor $p_{f}=1312$ was introduced, as depicted in Fig. 3(a); this price floor is above the equilibrium price interval for the efficient quality $B$. The stable outcome induced by this price floor is described in case 2 of Theorem 4, since

$$
1312=p_{f}<p^{\min }(C)-[v(C)-v(B)]=1390
$$

Hence, from Theorem 4, we have that in any stable outcome the quality $B$ will trade at the price floor of 1312 , while quality $C$ will trade at 1512 , the price floor plus the value to the buyer of an increase in quality from $B$ to $C$. The total quantity traded will be 38 units when there are 8 sellers and 8 buyers present. Total market surplus is in the interval $[28200,41800]$ in any stable outcome.

In session 2.2, a price floor $p_{f}=1470$ was introduced, as depicted in Fig. 3(b). The stable outcome induced by this price floor is described in case 3 of Theorem 4 , since

$$
1470=p_{f}>p^{\max }(C)-[v(C)-v(B)]=1410
$$


Hence, from Theorem 4, we have that in any stable outcome the quality $B$ will not be traded, while quality $C$ will trade in the interval $[1590,1610]$. The total quantity traded will be 34 units, and total market surplus is 26860 in any stable outcome; this outcome is depicted as the crossing of the supply and demand curves for quality $C$ in Fig. 3(b).

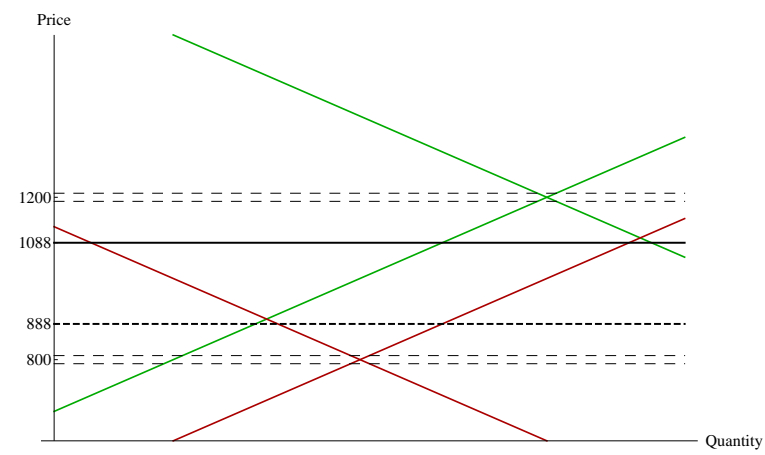

(a) $p_{f}=1312$.

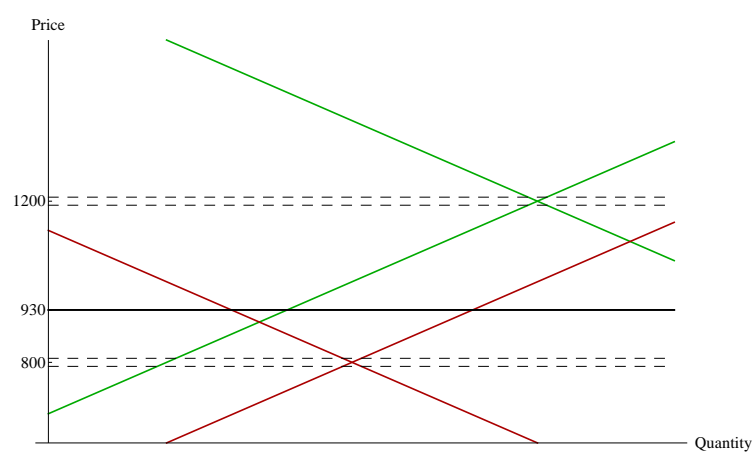

(b) $p_{f}=1470$.

Figure 4: In each subfigure, the green lines denote the supply and demand for the efficient quality $B$, while the red lines denote the supply and demand for the inefficiently low quality $A$; the dashed lines at 1190 and 1210 denote $p^{\min }(B)$ and $p^{\max }(B)$, while the dashed lines at 790 and 880 denote $p^{\min }(A)$ and $p^{\max }(A)$. In Fig. 4(a), the black line at 1088 denotes the price ceiling at which quality $B$ goods trade, while the dashed line at 88 denotes the price at which quality $A$ goods trade. In Fig. 4(b), the black line at 930 denotes the price floor; in this case, only quality $A$ goods trade, and do so at a price in the interval $[790,810]$.

Analogous arguments apply to the case of price ceilings. In session 2.3, a price ceiling $p_{c}=1088$ was imposed, as depicted in Fig. 4(a); this price floor is below the equilibrium price interval for the efficient quality $B$. The stable outcome induced by this price floor is described in case 2 of Theorem 5 , since

$$
1088=p_{c}>p^{\max }(A)+[e(B)-e(A)]=1010 .
$$

Hence, from Theorem 5 , we have that in any stable outcome the quality $B$ will trade at the price ceiling of 1088 , while quality $A$ will trade at 888 , the price ceiling minus the extra cost to the seller of an increase in quality from $A$ to $B$. The total quantity traded will be 38 units, and the total market surplus is in the interval $[28200,41800]$ in any stable outcome.

In session 2.4, a price ceiling of $p_{c}=930$ was introduced, as depicted in Fig. 4(b). The 
stable outcome induced by this price ceiling is described in case 3 of Theorem 5, since

$$
930=p_{c}<p^{\min }(A)+[e(B)-e(A)]=990 .
$$

Hence, from Theorem 5, in any stable outcome, the quality $B$ will not be traded, while quality $A$ will trade in the interval $[790,810]$. The total quantity traded will be 34 units, and the total market surplus is 24860 in any stable outcome with 8 sellers and 8 buyers; this outcome is depicted as the crossing of the supply and demand curves for quality $C$ in Fig. 3(b). Note that in session 2.4 there were only 7 buyers and 7 sellers. The theoretical predictions of the trading price remain the same but the stable outcome now entails only 30 units of quality $A$ being traded. The total market surplus is 24060 in any stable outcome with 7 sellers and 7 buyers.

A summary of all predictions is given in the table below.

Table: Theoretical predictions ( 8 sellers and 8 buyers)

\begin{tabular}{cccccc}
\hline & & Quality & Quantity & Price & Total surplus \\
\hline Series 1 & No price control & $D$ & 44 & {$[4482,4487]$} & 73458 \\
& Price floor 6000 & $G$ & 32 & 6000 & 48464 \\
Series 2 & & & & & \\
& No price control & B & 44 & {$[1190,1210]$} & 42460 \\
& Price floor 1312 & B and C & 38 & $1312(\mathrm{~B}), 1512(\mathrm{C})$ & {$[28200,41800]$} \\
& Price floor 1470 & C & 34 & {$[1590,1610]$} & 26860 \\
& Price ceiling 1088 & A and B & 38 & $888(\mathrm{~A}), 1088(\mathrm{~B})$ & {$[28200,41800]$} \\
& Price ceiling 930 & A & 34 & {$[790,810]$} & 26860 \\
\hline
\end{tabular}




\section{Results}

\subsection{Series 1 (Ten Qualities)}

Our first result shows that in the sessions with ten qualities and no price restrictions play converged to a stable outcome. This series is important as general equilibrium experiments with multiple qualities have not been conducted heretofore.

Result 1. In the absence of any price restrictions for the Series 1 market, the number of goods traded, the equilibrium price of the efficient quality, and the market efficiency all converge to competitive equilibrium/stable outcome values.

Table 4 shows market efficiency in each period for each session in Series 1. When no price restrictions are imposed, the average efficiency is over $90 \%$ for all sessions, except for session 1.2 in which there are only three periods. However, the market efficiency reaches 95.2\% in the third period in this session. Efficiency also tends to rise in the later periods of session 1.1. The average number of units traded by period, 42.5, is also very close to the theoretical prediction of the competitive equilibrium, 44 .

Table 5 summarizes the proportion of trade by quality during the second half of periods 5-7 in session 1.1. 62.1\% of trades are for quality $D$ goods while, in any stable outcome or competitive equilibrium, we expect $100 \%$ of trades to take place for quality $D$ goods; however, the proportion of goods traded at quality $D$ does clearly rise thoughout the experiments. Prices for quality $D$ goods are very close to competitive equilibrium prices. The average traded price in for quality $D$ goods is 4503.7 during the second half of Periods 5-7 in session 1.1, while the range of competitive equilibrium prices is $[4482,4487]$; the difference between the average traded price and the theoretical prediction is $0.3 \%$.

Statistical testing of static equilibrium models is enhanced by the use of the time series of the price discovery process. Following the methodology of Noussair et al. $(1995,1997)$ and Myagkov and Plott (1997), we estimate the Ashenfelter/El-Gamal model of market convergence for our data. This model assumes that the average price for each experiment 
may start from a different origin but all markets will experience adjustment, as described by a common functional form, and converge to a common aysymptotic value.

The parameter of interest for the Series 1 experiments when no price control is imposed is the equilibrium price of quality $D$. Hence, we estimate

$$
\bar{p}_{i}^{t}(D)-\frac{p^{\min } D+p^{\max }(D)}{2}=\beta_{1} d_{1} \frac{1}{t}+\beta_{2} d_{2} \frac{1}{t}+\beta_{4} d_{4} \frac{1}{t}+\gamma\left(1-\frac{1}{t}\right)+u_{i}^{t}
$$

where $i$ indicates the particular experiment, and $t$ represents time as measured by the number of market periods in the experiment. We let $\bar{p}_{i}^{t}(D)$ denote the mean traded price in period $t$; recall that the theoretical prediction is that the price lies in the interval $\left[p^{\min }(D), p^{\max }(D)\right]$. We let $d_{i}$ be a dummy variable that takes a value of 1 for the experiment $i$, and 0 otherwise; we do not use the data from Session 1.5 because there are only two periods in which a price control was not imposed. For session 1.4, we use data only from periods 4 to 7 , i.e. those periods in which a price control was not imposed. The parameter $\beta_{i}$ represents the the origin of a possible convergence process for session $i$. The paramter $\gamma$ represents the asymptotic difference between the common asymptotic value and the theoretical prediction; hence, $\gamma$ will be close to 0 if the difference between the traded prices and the theoretical prediction approaches 0 toward the end of each experiment. The random error term $u_{i}^{t}$ is distributed normally with mean zero.

Table 6 contains the estimation results. The estimated coefficient of $\gamma$ is not significantly different from 0 , indicating that the traded prices of quality $D$ are not significantly different from the midpoint of the theoretical prediction near the end of the experimental sessions.

Result 2. When a price floor of 6000 is imposed for the Series 1 market, the quality of goods traded, the traded prices, the number of goods traded, and the market efficiency converge to stable outcome values.

Table 4 shows that when the price floor of 6000 is imposed, the average market efficiency converges to the efficiency predicted by the theory. In the stable outcome, $66 \%$ of the possible efficiency gains are realized, while the average market efficiency in the experimental sessions 


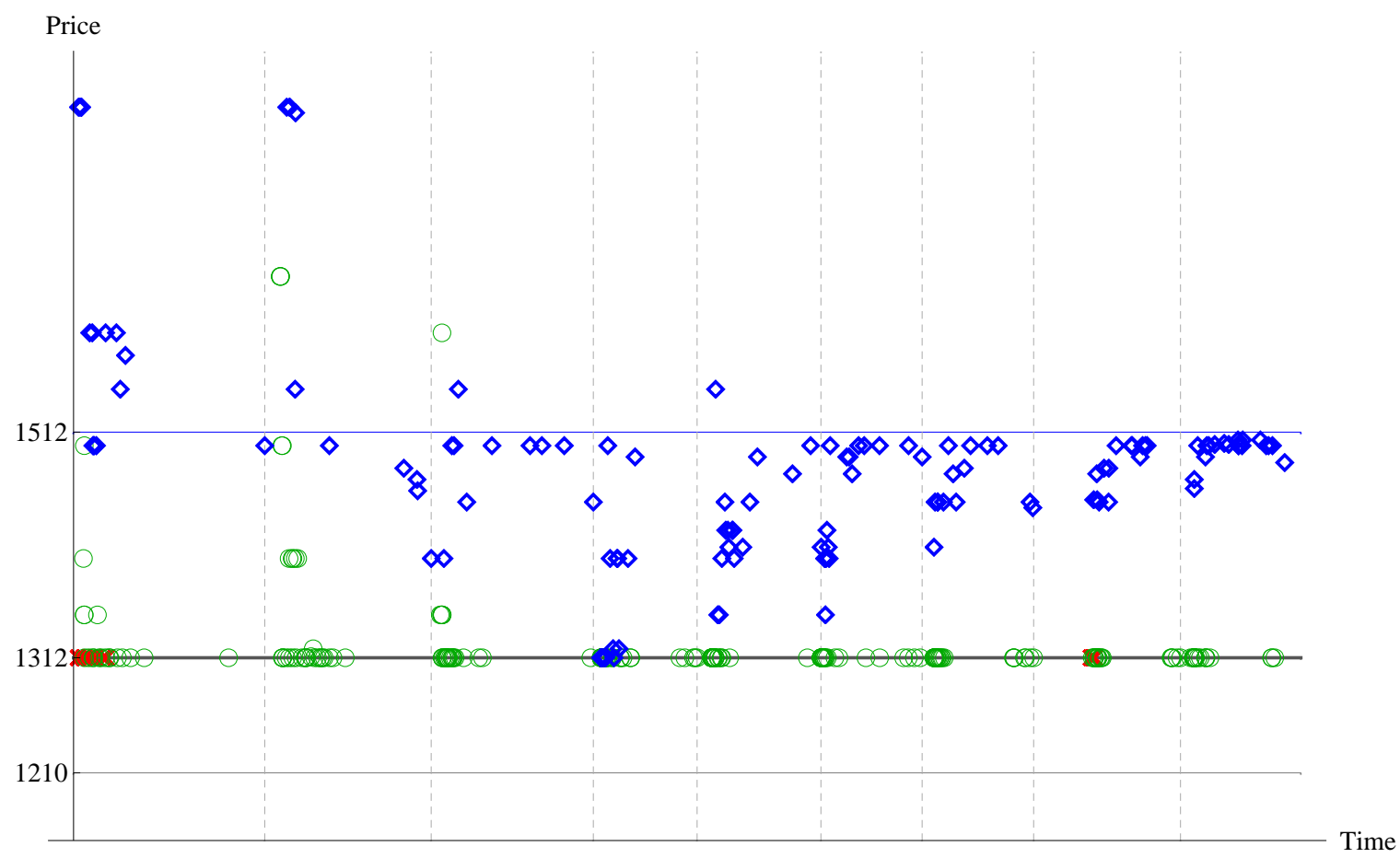

Figure 5: Experimental data for session 2.1 when a price floor of 1312, denoted by the thick gray line, was imposed. The blue diamonds denote trades of the high quality good (quality $C$ ), the green circles trades of the medium quality good (quality $B$ ), and red crosses trades of the low quality good (quality $A$ ). The thin blue line at 1512 denotes the predicted price of trades with high quality goods. The experiment took place over 9 periods, delineated by the vertical dashed gray lines.

was $62.4 \%$. Table 5 shows that $83.6 \%$ percent of trades are for quality $G$ goods during the second half of periods 5-8 of session 1.3 and periods 5-6 of session 1.5. All traded prices were 6000 during these periods, obviating the need for statistical analysis, as the theoretical prediction matched the experimental outcome exactly. The average number of trades per period was also very close to the stable outcome values for each session, as shown in Table 4.

\section{$5.2 \quad$ Series 2 (Three Qualities)}

Result 3. When a price floor of 1312 is imposed for the Series 2 market, the traded prices, the number of goods traded, the quality of goods traded, and the market efficiency converge to stable outcome values.

Table 7 shows the market efficiency in all periods in session 2.1 in which a price floor 
of 1312 was imposed. Market efficiency is within the theoretical prediction, the interval of $[0.664,0.984]$, in all periods. The average number of units traded is 41.4 , which is within $8.9 \%$ of the theoretical prediction of 38 . Table 8 summarizes the proportion of trade by quality during the second half of all periods. $98.4 \%$ percent of trades took place either at quality $B$ or $C$, as predicted by the theory.

Figure 5 shows traded prices in session 2.1. Quality $B$ goods are often traded at the price floor of 1312. In the last 2 periods, all trades were made at the price floor of 1312 in quality $B$, as the theory predicts. The average traded price for quality $C$ in the last two periods is 1490, which is slightly below the theoretical prediction of 1512 .

Result 4. When a price floor of 1470 is imposed for the Series 2 market, the number of goods traded, the quality of goods traded, the equilibrium prices, and the market efficiency all converge to stable outcome values.

Table 7 shows the market efficiency in all periods in session 2.2 in which a price floor of 1470 was imposed. The average market efficiency is $69.3 \%$, which is slightly higher than the theoretical prediction of $63.3 \%$. The average number of units traded is 35.5 , which is very close to the theoretical prediction of 34 . Table 8 summarizes the proportion of trade by quality during the second half of all periods. $93.1 \%$ of trades were for quality $C$ goods, largely in agreement with the theoretical prediction that all trade will take place at that quality.

Figure 6 shows prices for each transaction in session 2.2; prices for quality $C$ goods are very close to the theoretical prediction. The average price is 1589 for a quality $C$ good during the last two periods of the session when the price floor was imposed, compared to a theoretical prediction of $[1590,1610]$.

Figure 6 also shows how quickly the market adjusts to the competitive equilibrium. As soon as the price floor is removed, trade shifts from quality $C$ goods to quality $B$ goods, and quality $B$ goods are traded at the prices suggested by theory. Furthermore, efficiency rose to nearly $100 \%$. The average trading price for quality $B$ is 1192 during the last two periods, 


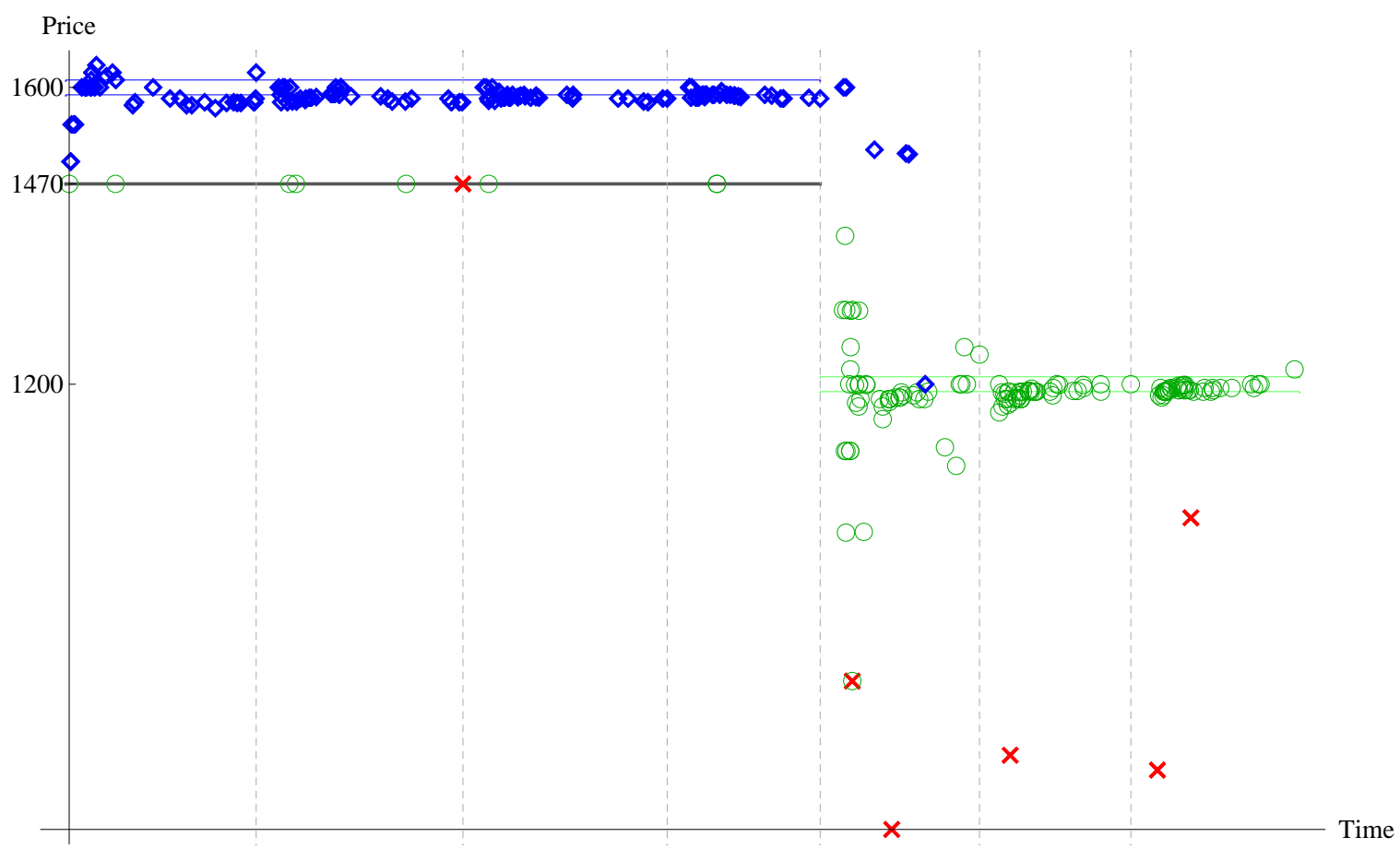

Figure 6: Experimental data for session 2.2 when a price floor of 1470, denoted by the thick gray line, was imposed. The blue diamonds denote trades of the high quality good (quality $C$ ), the green circles trades of the medium quality good (quality $B$ ), and red crosses trades of the low quality good (quality $A$ ). The thin blue lines at 1590 and 1610 denote the range of predicted prices of trades with high quality goods. The experiment took place over 7 periods, delineated by the vertical dashed gray lines. The price floor was removed after Period 4 .

which falls with the theoretically predicted interval of $[1190,1210]$.

Result 5. When a price ceiling of 1088 is imposed for the Series 2 market, the number of goods traded, the quality of goods traded, the equilibrium prices, and the market efficiency all converge to stable outcome values.

Table 7 shows the market efficiency in all periods in session 2.3 in which a price ceiling of 1088 was imposed. Market efficiency is within the theoretical prediction, the interval of $[0.664,0.984]$, in all periods. The average number of trades in a period is 43.6 , which is higher than the theoretical prediction of 38 . However, the average number of trades is 40.5 for the last two periods, within $7 \%$ of the theoretical prediction. Table 8 summarizes the proportion of trades by quality during the second half of all periods. $98.2 \%$ of trades took place at quality $A$ or $B$, as predicted by the theory. 


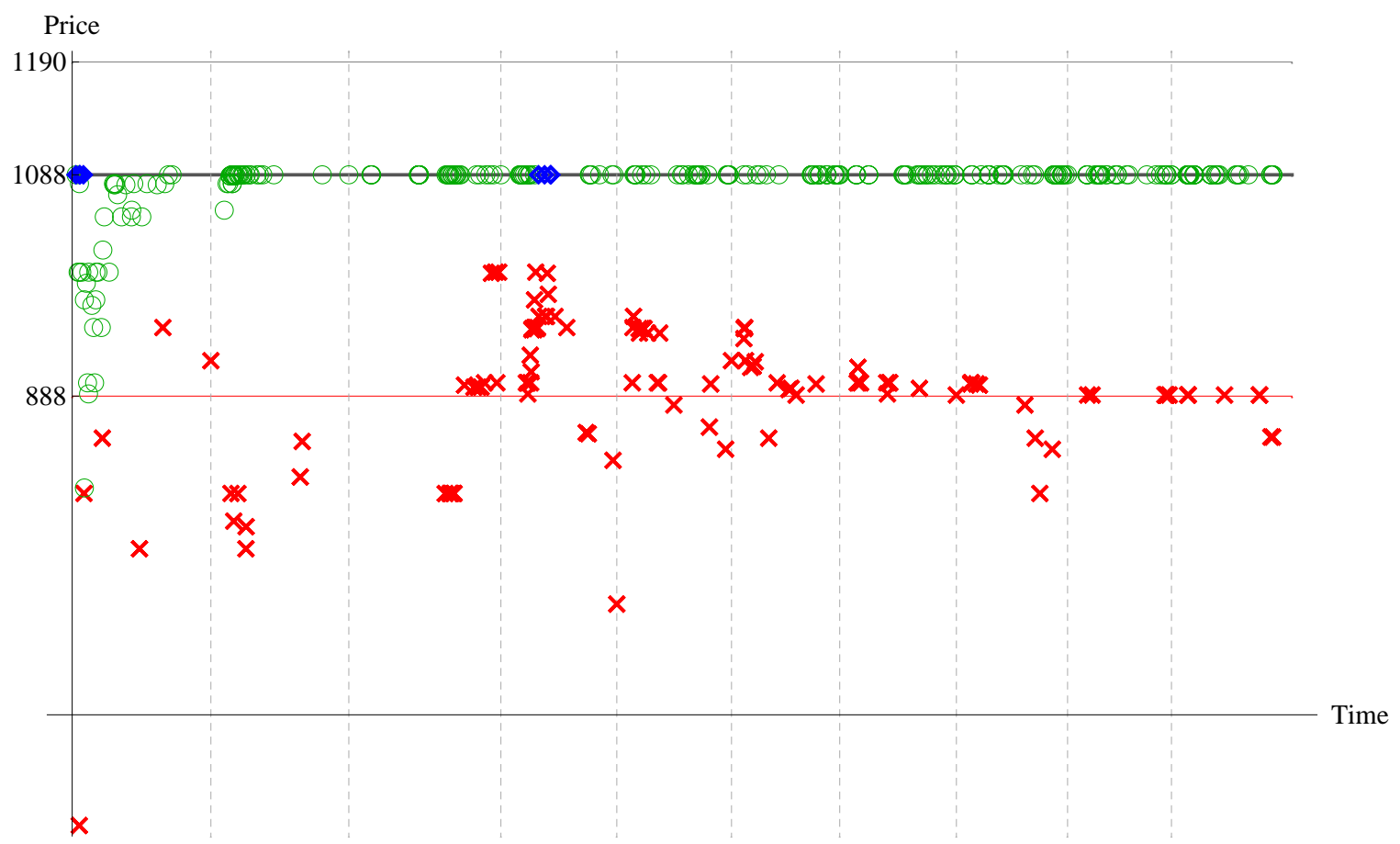

Figure 7: Experimental data for session 2.3 when a price ceiling of 1088, denoted by the thick gray line, was imposed. The blue diamonds denote trades of the high quality good (quality $C$ ), the green circles trades of the medium quality good (quality B), and red crosses trades of the low quality good (quality $A$ ). The thin red line at 888 denotes the predicted prices of trades of quality $A$ goods.

Figure 7 shows prices for each transaction in session 2.3. The average prices for both quality $A$ and $B$ goods are very close to the theoretical prediction. The average traded price of Quality $A$ in the last two periods is 884 , which is not significantly different from the theoretical prediction of 888 , and the average price for quality B goods is 1088 in the last two periods, which is exactly the same as the theoretical prediction.

Result 6. When a price ceiling of 930 is imposed for the Series 2 market, the number of goods traded, the quality of goods traded, the equilibrium prices, and the market efficiency all converge to stable outcome values.

Table 7 shows market efficiency in all periods in session 2.4 in which a price ceiling of 930 was imposed. The average market efficiency across periods was $69 \%$, which is slightly higher than the theoretical prediction of $63.5 \%$. The average number of trades is 31.5 , which is also only slightly higher than the theoretical prediction of 30 . Table 8 summarizes the 


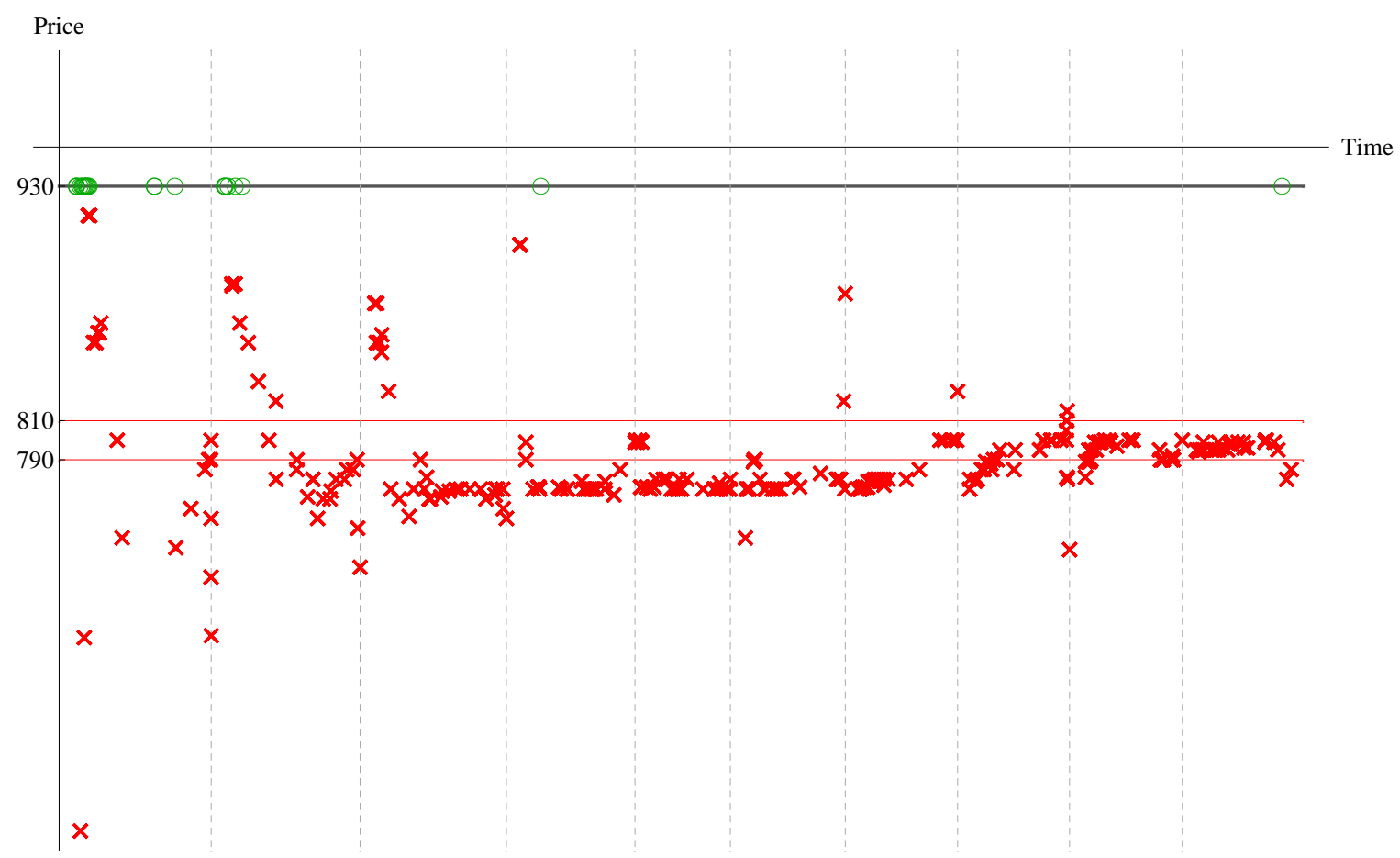

Figure 8: Experimental data for session 2.4 when a price ceiling of 930, denoted by the thick gray line, was imposed. The green circles trades of the medium quality good (quality $B$ ), and red crosses trades of the low quality good (quality $A$ ). The thin red lines at 790 and 810 denote the range of predicted prices of trades of low quality goods.

proportion of trade by quality during the second half of all periods. $97.5 \%$ of trades were for quality $A$ goods, largely in agreement with the theoretical prediction that all trade will take place at that quality.

Figure 8 shows prices for each transaction in session 2.4. Prices for quality $A$ goods are concentrated within the range of the theoretical prediction during the last three periods. The average price during the last two periods is 795 for quality $A$ goods, which is within the range of the theoretical prediction of $[790,810]$.

We also estimate the Ashenfelter/El-Gamal model of market convergence for Series 2. We first consider price controls that result in outcomes described in the second part of Theorems 4 and 5. Hence, we estimate the difference between the traded price and the theoretical prediction for session 2.1 and 2.3 of quality $C$ and quality $A$ goods, respectively, 
denoting this $\bar{Y}_{i}^{t}$. We estimate

$$
\bar{Y}_{i}^{t}=\beta_{1} d_{1} \frac{1}{t}+\beta_{3} d_{3} \frac{1}{t}+\gamma\left(1-\frac{1}{t}\right)+u_{i}^{t}
$$

where we let $i$ denote the particular experiment, and $t$ denote time as measured by the number of market periods in the experiment. We use the difference between mean traded prices and theoretical predictions as a dependent variable, instead of mean traded prices, as theoretical predictions differ across different treatments.

Table 6 contains the estimation results. The estimated coefficient of $\gamma$ is not significantly different from 0 , indicating that the traded prices are not significantly from the theoretical predictions different near the end of the experimental sessions in this regime.

We then consider price controls that result in outcomes described in the third parts of Theorems 4 and 5. Hence, we estimate the difference between the traded price and the theoretical prediction for sessions 2.2 and 2.4 of quality $C$ and quality $A$ goods, respectively. In session 2.2 , the price floor was removed after period 4 and so we only use data until period 4. We estimate

$$
\bar{p}_{i}^{t}(q)-\frac{p^{\min }(q)+p^{\max }(q)}{2}=\beta_{2} d_{2} \frac{1}{t}+\beta_{4} d_{4} \frac{1}{t}+\gamma\left(1-\frac{1}{t}\right)+u_{i}^{t}
$$

where $q=C$ when a price floor is imposed, and $q=A$ when a price ceiling is imposed.

Table 6 contains the estimation results. Note that the model predicts that $\gamma$ will fall within the interval $[-10,10]$, as $p^{\max }(q)-p^{\min }(q)=20$ for this experiment for all $q \in Q$; the estimated coefficient of $\gamma$ is -8.3 , indicating that trade near the end of the experimental sessions is occurring at prices within the theoretically predicted interval.

\section{Conclusion}

We have demonstrated that while in buyer-seller models with heterogenous quality competitive equilibria may not exist when price controls are present, matching-theoretic stable outcomes do exist. Furthermore, the predictions of the quality competition model accurately 
predict the behavior of subjects in the laboratory. This experimental agreement is particularly surprising given the imperfect information available to experimental subjects: they were informed only of their own valuations and not those of other participants.

The work presented here suggests that matching theory can provide a theoretical basis for the intuition that price controls induce non-price competition. The theoretical predictions of Theorems 4 and 5 show that observed quality responds in ways suggested by economic intuition to price controls. Furthermore, these effects were also seen in the data.

This work also suggests that matching theory and other cooperative game-theoretic approaches may be useful in other contexts in which competitive equilibria fail to exist. For instance, when production quotas are imposed (such as due to trade restrictions), competitive equilibria may fail to exist, but such economies may be able to be modeled within the framework of matching theory, as suggested by Ostrovsky (2008). ${ }^{18}$ Similarly, in settings with fixed costs, competitive equilibria often fail to exist due to the nonconvexities inherent in those settings (see, e.g., Eswaran et al. (1983)), and it may be that stable outcomes exist in some such markets. Finally, the model described here may also used to understand markets with imperfect competition - see the recent work by Azevedo and Leshno (2011) and Azevedo (2011). We conjecture that stability may provide a robust solution concept for predicting behavior in these settings as well.

\footnotetext{
${ }^{18}$ Indeed, the work of Ostrovsky (2008) suggests that such constraints may be incorporated even when the quota-restricted good is an input to a downstream production process.
} 


\section{References}

Azevedo, E. M. (2011). Imperfect competition in two-sided matching markets. Mimeo, Harvard Business School.

Azevedo, E. M. and J. D. Leshno (2011). The college admissions problem with a continuum of students. In Proceedings of the 12th ACM conference on Electronic commerce, pp. $333-334$.

Bevia, C., M. Quinzii, and J. Silva (1999). Buying several indivisible goods. Mathematical Social Sciences 37(1), 1-23.

Crockett, S., R. Oprea, and C. Plott (2011). Extreme walrasian dynamics: The gale example in the lab. American Economic Review 101, 3196-3220.

Douglas, G. W. and J. C. Miller III (1974). Quality competition, industry equilibrium, and efficiency in the price-constrained airline market. The American Economic Review 64(4), $657-669$.

Dréze, J. (1975). Existence of an exchange equilibrium under price rigidities. International Economic Review 16(2), 301-320.

Echenique, F. and J. Oviedo (2006). A theory of stability in many-to-many matching markets. Theoretical Economics 1, 233-273.

Eswaran, M., T. R. Lewis, and T. Heaps (1983). On the nonexistence of market equilibria in exhaustible resource markets with decreasing costs. Journal of Political Economy, $154-167$.

Feldstein, M. (1973). The economics of the new unemployment. The Public Interest 33, $3-42$.

Gul, F. and E. Stacchetti (1999). Walrasian equilibrium with gross substitutes. Journal of Economic Theory 87, 95-124. 
Hammond, P., M. Kaneko, and M. Wooders (1989). Continuum economies with finite coalitions: Core, equilibria, and widespread externalities. Journal of Economic Theory 49(1), $113-134$.

Hashimoto, M. (1982). Minimum wage effects on training on the job. The American Economic Review Papers and Proceedings 72(5), 1070-1087.

Hatfield, J. W. and S. D. Kominers (2011). Contract design and stability in matching markets. Mimeo, Harvard Business School.

Hatfield, J. W. and S. D. Kominers (Forthcoming, 2012). Matching in Networks with Bilateral Contracts. American Economic Journal: Microeconomics.

Hatfield, J. W., S. D. Kominers, A. Nichifor, M. Ostrovsky, and A. Westkamp (2011). Stability and competitive equilibrium in trading networks. Mimeo, Stanford Graduate School of Business.

Hatfield, J. W. and P. Milgrom (2005). Matching with contracts. American Economic Review 95, 913-935.

Hatfield, J. W., C. R. Plott, and T. Tanaka (2012). Understanding price controls and non-price competition through matching theory. American Economic Review Papers 83 Proceedings.

Holt, C. (1995). Industrial organization: A survey of laboratory research. The handbook of experimental economics 349, 402-03.

Isaac, R. M. and C. R. Plott (1981). Price controls and the behavior of auction markets: An experimental examination. The American Economic Review 71(3), 448-459.

Jaume, D., J. Massó, and A. Neme (2009). The multiple-partners assignment game with heterogeneous sells and multi-unit demands: Competitive equilibria. Mimeo. 
Joskow, P. L. (1980). The effects of competition and regulation on hospital bed supply and the reservation quality of the hospital. The Bell Journal of Economics 11(2), 421-447.

Kaneko, M. and M. Wooders (1986). The core of a game with a continuum of players and finite coalitions: The model and some results. Mathematical Social Sciences 12(2), $105-137$.

Kaneko, M. and M. Wooders (1996). The nonemptiness of the f-core of a game without side payments. International Journal of Game Theory 25(2), 245-258.

Kirchsteiger, G., M. Niederle, and J. Potters (2005). Endogenizing market institutions: An experimental approach. European Economic Review 49(7), 1827-1853.

Leffler, K. (1982). Ambiguous changes in product quality. The American Economic Review 72(5), 956-967.

Myagkov, M. and C. R. Plott (1997). Exchange economies and loss exposure: Experiments exploring prospect theory and competitive equilibria in market environments. American Economic Review 87(5), 801-828.

Neumark, D. and W. Wascher (2001). Minimum wages and training revisited. Journal of Labor Economics 19(3), 563-595.

Noussair, C. N., C. R. Plott, and R. G. Riezman (1995). An experimental investigation of the patterns of international trade. American Economic Review 85(3), 462-491.

Noussair, C. N., C. R. Plott, and R. G. Riezman (1997). The principles of exchange rate determination in an international finance experiment. Journal of Political Economy 105(4), $822-861$.

Ostrovsky, M. (2008). Stability in supply chain networks. American Economic Review 98, $897-923$. 
Plott, C. R. (1965). Occupational self-regulation: A case study of the oklahoma dry cleaners. The Journal of Law and Economics 8, 195-222.

Plott, C. R. (1982). Industrial organization theory and experimental economics. journal of Economic Literature 20(4), 1485-1527.

Plott, C. R., T. Tanaka, and M. Jones (2007). Quality adjustment, the assignment core, and the non-existence of general competitive equilbrium: Price ceilings and floors in an experimental multi-market system. Mimeo, California Institute of Technology.

Sotomayor, M. A. O. (2007). Connecting the cooperative and competitive structures of the multiple-partners assignment game. Journal of Economic Theory 134, 155-174.

Sotomayor, M. A. O. (2009). Adjusting prices in the multiple-partners assignment game. International Journal of Game Theory 38, 1-26.

van der Laan, G. (1980). Equilibrium under rigid prices with compensation for the consumers. International Economic Review 21(1), 63-73. 


\section{A Proofs}

\section{A.1 Proof of Theorem 1}

See Theorems 6 and 10 in Hatfield et al. (2011).

\section{A.2 Proof of Theorem 2}

Existence follows from Theorem 2 in Hatfield et al. (2011). The quantity predicted is the efficient quantity, and that is part of any stable outcome: see Theorems 3 and 7 in Hatfield et al. (2011).

For the final part of the proof, we need to show that all contracts $\left(\omega, p_{\omega}\right) \in A$ transact at a price $p_{\omega} \in\left[p^{\min }(\bar{q}), p^{\max }(\bar{q})\right]$. There are two cases to consider:

1. Suppose that $p_{\omega}<p^{\min }(\bar{q})$ There are two cases to consider:

(a) Suppose that $p_{\omega}<f^{b}\left(\left|A_{b}\right|+1\right)-f^{b}\left(\left|A_{b}\right|\right)+v(b)$ for some buyer $b$. Then there exists a blocking set of the form $\left\{\left(\psi, p_{\psi}\right)\right\}$ where $\mathrm{b}(\psi)=b$ and $\mathbf{s}(\psi)=s(\omega)$ along with a price

$$
p_{\psi}=\frac{\left(f^{b}\left(\left|A_{b}\right|+1\right)-f^{b}\left(\left|A_{b}\right|\right)+v(\bar{q})\right)+p_{\omega}}{2} .
$$

as both seller and buyer will choose this contract.

(b) Suppose that $p_{\omega}<c^{s}\left(\left|A_{s}\right|\right)-c^{s}\left(\left|A_{s}\right|-1\right)+e(\bar{q})$ for some seller $s=\mathbf{s}(\omega)$. Then $A$ is not individually rational for $S$, as $A_{s}-\left\{\left(\omega, p_{\omega}\right)\right\}$ makes $s$ strictly better off.

2. The proof that $p_{\omega}<p^{\max }(\bar{q})$ is analogous.

\section{A.3 Proof of Theorem 3}

From Theorems 2, 3, and 6 of Hatfield et al. (2011) a stable outcome exists and is efficient. Hence it must only include contracts with quality $\hat{q}$. The bounds on the prices then follow from the same arguments as in the proof of Theorem 2. 


\section{A.4 Proof of Theorem 4}

We first prove existence of a stable outcome. We let

$$
\bar{p}^{B} \equiv \max _{b \in B} f^{b}(1)-f^{b}(0)+v\left(q^{\max }\right)+1
$$

note that no contract $\left(\omega, p_{\omega}\right)$ with a price $p_{\omega}>\bar{p}^{B}$ can be individually rational for any buyer, and so without loss of generality we may consider the contractual set $\bar{X}\left[p_{f}\right] \equiv\{x \in$ $\left.X: \mathrm{p}(x) \in\left[p_{f}, \bar{p}^{B}\right]\right\}$.

$$
\begin{aligned}
& P^{B}(Z) \equiv\left\{\left(\omega, p_{\omega}\right) \in X\left[p_{f}, \bar{p}^{B}\right]: p_{\omega}=\inf _{\left(\omega, p_{\omega}\right) \in Z} p_{\omega}\right\} \\
& P^{S}(Z) \equiv\left\{\left(\omega, p_{\omega}\right) \in X\left[p_{f}, \bar{p}^{B}\right]: p_{\omega}=\sup _{\left(\omega, p_{\omega}\right) \in Z} p_{\omega}\right\}
\end{aligned}
$$

We consider a model with augmented preferences, where each agent $i$ is endowed with a strict ordering $\omega^{1} \succ_{i} \ldots \succ_{i} \omega^{K_{i}}$ over trades involving $i$. This induces a strict ordering $\triangleright_{i}$ over sets such that

$$
\hat{Z} \triangleright_{i} Z \Leftrightarrow|\hat{Z}|<|Z| \text { or } \max _{\succ_{i}} \tau(Z) \sqcup \tau(\hat{Z}) \in \tau(\hat{Z})
$$

We define an augmented choice function on $\tilde{X}\left[p_{f}\right]$

$$
\hat{C}^{b}(Y) \equiv \max _{\triangleright_{b}}\left\{Z \in C^{b}\left(P^{B}(Y)\right)\right\}
$$

for each $b \in B$ and

$$
\hat{C}^{s}(Y) \equiv \max _{\triangleright_{s}}\left\{Z \in C^{s}\left(P^{S}(Y)\right)\right\}
$$

for each $s \in S$, where $\max _{\triangleright}$ denotes the maximal set according to the order $\triangleright$. Note that this is a choice function, not a choice correspondence. Existence of a stable outcome $A$ for these augmented preferences then follows as the existence proof in Hatfield and Kominers (2011) - note that the assumption of a finite contractual set is not required for the proof of existence in that work. Finally, since $\hat{C}^{i}(Y) \in C^{i}(Y)$ for all $i \in B \cup S$ and all $Y \subseteq X, A$ is a stable outcome for the original preferences.

We now characterize the set of stable outcomes, given the price restriction for each case. There are three cases to consider: 
1. $p_{f}<p^{\max }(\hat{q})$ : Then the outcome described in Theorem 3 is still feasible, and hence is stable as it is still individually rational and unblocked. (Note that all blocking sets would also be blocking sets for the model with no price restrictions.)

2. $p^{\max }(q)<p_{f}<p^{\min }(q+1)-[v(q+1)-v(q)]$ : We proceed in several steps:

(a) We first show that $p_{\psi}=p_{\omega}+[v(\mathbf{q}(\psi))-v(\mathbf{q}(\omega))]$ for all $\left(\psi, p_{\psi}\right),\left(\omega, p_{\omega}\right) \in A$ where $\mathbf{q}(\psi) \geq \mathbf{q}(\omega)$. There are two cases.

i. If $p_{\psi}<p_{\omega}+[v(\mathbf{q}(\psi))-v(\mathbf{q}(\omega))]$, we have that $Z=\left\{\left(\chi, p_{\chi}\right)\right\}$ is a blocking set, where $\mathbf{b}(\chi)=\mathbf{b}(\omega), \mathbf{s}(\chi)=\mathbf{s}(\psi), \mathbf{q}(\chi)=\mathbf{q}(\psi)$ and

$$
p_{\chi}=\frac{p_{\psi}+\left[p_{\omega}+[v(\mathbf{q}(\psi))-v(\mathbf{q}(\omega))]\right]}{2} .
$$

This contract is chosen from $A \cup\left\{\left(\chi, p_{\chi}\right)\right\}$ by $\mathrm{b}(\chi)$, as it is strictly better for $\mathrm{b}(\chi)$ than $\left(\omega, p_{\omega}\right)$; it is also chosen from $A \cup\left\{\left(\chi, p_{\chi}\right)\right\}$ by $\mathrm{s}(\chi)$, as it is strictly better for $\mathbf{s}(\chi)$ than $\left(\psi, p_{\psi}\right) \cdot{ }^{19}$

ii. If $p_{\psi}>p_{\omega}+[v(q(\psi))-v(q(\omega))]$, we have that $Z=\left\{\left(\chi, p_{\chi}\right)\right\}$ is a blocking set, where $\mathbf{b}(\chi)=\mathrm{b}(\psi), \mathrm{s}(\chi)=\mathrm{s}(\omega), \mathrm{q}(\chi)=\mathrm{q}(\omega)$ and

$$
p_{\chi}=\frac{p_{\omega}+\left[p_{\psi}-[v(q(\psi))-v(q(\omega))]\right]}{2} .
$$

This contract is chosen from $A \cup\left\{\left(\chi, p_{\chi}\right)\right\}$ by $\mathrm{b}(\chi)$, as it is strictly better for $\mathrm{b}(\chi)$ than $\left(\psi, p_{\psi}\right)$; it is also chosen from $A \cup\left\{\left(\chi, p_{\chi}\right)\right\}$ by $\mathbf{s}(\chi)$, as it is strictly better for $\mathbf{s}(\chi)$ than $\left(\omega, p_{\omega}\right) .{ }^{20}$

(b) We now show that there are at most two consecutive qualities. Suppose not. Then there exist $\left(\psi, p_{\psi}\right),\left(\omega, p_{\omega}\right) \in A$ where $\mathbf{q}(\psi)>\mathbf{q}(\omega)+1$. Consider the contract $\chi$ where $\mathbf{b}(\chi)=\mathbf{b}(\psi), \mathbf{s}(\chi)=\mathbf{s}(\psi), \mathbf{q}(\chi)=\mathbf{q}(\psi)-1$, and

$$
p_{\chi}=p_{\psi}-[v(\mathbf{q}(\psi))-v(\mathbf{q}(\psi)-1)]-\epsilon
$$

\footnotetext{
${ }^{19}$ Note that $\left(\chi, p_{\chi}\right)$ must be individually rational, as $\left(\psi, p_{\psi}\right)$ and $\left(\omega, p_{\omega}\right)$ were individually rational for $\mathrm{b}(\chi)$ and $\mathbf{s}(\chi)$, respectively.

${ }^{20}$ Note that $\left(\chi, p_{\chi}\right)$ must be individually rational, as $\left(\omega, p_{\omega}\right)$ and $\left(\psi, p_{\psi}\right)$ were individually rational for $\mathrm{b}(\chi)$ and $\mathbf{s}(\chi)$, respectively.
} 
for some small $\epsilon>0$. Note that from part 2a, $p_{\psi}=p_{\omega}+[v(q(\psi))-v(q(\omega))]$, which implies that $p_{\chi}>p_{\omega} \geq p_{f}$ for $\epsilon>0$ small enough, and hence $\left(\chi, p_{\chi}\right)$ is a valid contract. $\left\{\left(\chi, p_{\chi}\right)\right\}$ is a blocking set, as both $\mathrm{b}(\chi)$ and $\mathbf{s}(\chi)$ are strictly better off dropping $\left(\psi, p_{\psi}\right)$ and choosing $\left(\chi, p_{\chi}\right) \cdot{ }^{21}$

(c) We now show that if two consecutive qualities are traded in a stable outcome $A$, then one of them is traded at the price floor $p_{f}$. Suppose not. Let $\left(\psi, p_{\psi}\right),\left(\omega, p_{\omega}\right) \in$ $A$ where $\mathrm{q}(\psi)=\mathrm{q}(\omega)+1$. Consider a contract $\left(\chi, p_{\chi}\right)$ such that $\mathrm{b}(\chi)=\mathrm{b}(\omega)$, $\mathbf{s}(\chi)=\mathbf{s}(\psi), \mathbf{q}(\chi)=\mathbf{q}(\omega)$, and $p_{\chi}=p_{\omega}-\epsilon$ for some small $\epsilon>0 .\left\{\left(\chi, p_{\chi}\right)\right\}$ is a blocking set for $\epsilon>0$ small enough, as both $\mathrm{b}(\chi)$ and $\mathbf{s}(\chi)$ are strictly better off dropping $\left(\omega, p_{\omega}\right)$ and $\left(\psi, p_{\psi}\right)$ and choosing $\left(\chi, p_{\chi}\right)$-note that the seller is better off as he gains almost all the surplus from switching to a more efficient quality. ${ }^{22}$

(d) We now show that the two traded qualities are $q$ and $q+1$. It will be helpful to define the following notation:

$$
\mathcal{M}(q) \equiv \underset{n \in \mathbb{Z}_{\geq 0}}{\arg \max }\left\{\sum_{b \in B}\left[f^{b}\left(n_{b}\right)+v(q)-p_{f}\right]\right\}
$$

where

$$
\sum_{b \in B} n_{b}=n
$$

To see that the two traded qualities are $q$ and $q+1$, suppose not; let the two traded qualities be $q^{\prime}$ and $q^{\prime}+1$. There are two cases to consider:

i. Suppose that $q^{\prime}>q$; hence, $p_{f}<p^{\min }\left(q^{\prime}\right)$. There are two subcases to consider:

- Suppose that

$$
p^{\min }\left(q^{\prime}\right)=\max _{b \in B}\left\{f^{b}\left(\left|\hat{A}_{b}\right|+1\right)-f^{b}\left(\left|\hat{A}_{b}\right|\right)+v\left(q^{\prime}\right)\right\} .
$$

for some $\hat{A}$ that is stable for the contract set $X\left(q^{\prime}\right)$. Then at the price $p_{f}$ the buyers strictly demand at least $m+1$ goods of quality $q^{\prime}$, where

\footnotetext{
${ }^{21}$ Note that $\left(\chi, p_{\chi}\right)$ must be individually rational, as $\left(\psi, p_{\psi}\right)$ was individually rational for $\mathrm{b}(\chi)$ and $\mathbf{s}(\chi)$.

${ }^{22}$ Note that $\left(\chi, p_{\chi}\right)$ must be individually rational, as $\left(\psi, p_{\psi}\right)$ and $\left(\omega, p_{\omega}\right)$ were individually rational for $\mathrm{b}(\chi)$ and $\mathrm{s}(\chi)$, respectively.
} 
$m=\max \mathcal{M}\left(q^{\prime}\right) ;$ however, there are at most $m$ sellers willing to trade a quality $q^{\prime}$ at a price $p_{f}$. Hence, either $A$ is not individually rational or there exists a blocking set $\left\{\left(\chi, p_{\chi}\right)\right\}$ where $q(\chi)=q^{\prime}$ and $p_{\chi}=p_{f}+\epsilon$ for $\epsilon>0$ small enough with a buyer whose demand is not satisfied and a current seller.

- Suppose that

$$
p^{\min }\left(q^{\prime}\right)=\max _{s \in S}\left\{c^{s}\left(\left|\hat{A}_{s}\right|\right)-c^{s}\left(\left|\hat{A}_{s}\right|-1\right)+e\left(q^{\prime}\right)\right\} .
$$

for some $\hat{A}$ that is stable for the contract set $X\left(q^{\prime}\right)$. Then at the price $p_{f}$ the buyers strictly demand at least $m$ goods of quality $q^{\prime}$, where $m=$ $\min \mathcal{M}\left(q^{\prime}\right)$; while there are at most $m-1$ sellers willing to trade a quality $q^{\prime}$ at a price $p_{f}$. Hence either $A$ is not individually rational or there exists a blocking set $\left\{\left(\chi, p_{\chi}\right)\right\}$ where $q(\chi)=q^{\prime}$ and $p_{\chi}=p_{f}+\epsilon$ for $\epsilon>0$ small enough with a buyer whose demand is not satisfied and a current seller.

ii. Suppose that $q^{\prime}<q$. hence, $p_{f}>p^{\max }\left(q^{\prime}+1\right)$. There are two subcases to consider:

- Suppose that

$$
p^{\max }\left(q^{\prime}+1\right)=\min _{b \in B}\left\{f^{b}\left(\left|\hat{A}_{b}\right|\right)-f^{b}\left(\left|\hat{A}_{b}\right|-1\right)+v\left(q^{\prime}+1\right)\right\} .
$$

for some $\hat{A}$ that is stable for the contract set $X\left(q^{\prime}+1\right)$. Then at the price $p_{f}$ the buyers demand at most $m-1$ goods of quality $q^{\prime}+1$ or less, where $m=\min \mathcal{M}\left(q^{\prime}+1\right)$; however, there are at least $m$ sellers willing to trade a quality $q^{\prime}+1$ or less at a price $p_{f}$. Hence either $A$ is not individually rational or there exists a blocking set $\left\{\left(\chi, p_{\chi}\right)\right\}$ where $\mathbf{q}(\chi)=q^{\prime}+1$ and $p_{\chi}=p_{f}+\left[v\left(q^{\prime}+1\right)-v\left(q^{\prime}\right)\right]-\epsilon$ for $\epsilon>0$ small enough with a seller who is not satisfied and a current buyer.

- Suppose that

$$
p^{\max }\left(q^{\prime}+1\right)=\min _{S \in S}\left\{c^{s}\left(\left|\hat{A}_{s}\right|\right)-c^{s}\left(\left|\hat{A}_{s}\right|-1\right)+e\left(q^{\prime}+1\right)\right\} .
$$


for some $\hat{A}$ that is stable for the contract set $X\left(q^{\prime}+1\right)$. Then at the price $p_{f}$ the buyers demand at most $m$ goods of quality $q^{\prime}+1$ or less, where $m=\max \mathcal{M}\left(q^{\prime}+1\right)$; however, there are at least $m+1$ sellers willing to trade a quality $q^{\prime}+1$ or less at a price $p_{f}$. Hence either $A$ is not individually rational or there exists a blocking set $\left\{\left(\chi, p_{\chi}\right)\right\}$ where $q(\chi)=q^{\prime}+1$ and $p_{\chi}=p_{f}+\left[v\left(q^{\prime}+1\right)-v\left(q^{\prime}\right)\right]-\epsilon$ for $\epsilon>0$ small enough with a seller who is not satisfied and a current buyer.

(e) The above results imply that if both $q$ and $q+1$ quality goods are traded, they must be traded at prices $p_{f}$ and $p_{f}+[v(q+1)-v(q)]$. If only quality $q$ is traded, it must be traded at $p_{f}$, as if any other contract of the form $\left(\omega, p_{\omega}\right)$ exists, there will exist a blocking set of the form $\left\{\left(\psi, \frac{p_{\omega}+p_{f}}{2}\right)\right\}$, as we know at a price $p_{f}>p^{\max }(q)$ more sellers will demand to sell a good of quality $q$ then there are buyers willing to buy such a good. If only quality $q+1$ is traded, then it must trade at $p_{f}+[v(q+1)-v(q)]$, as if there exists a contract for a quality $q+1$ good of the form $\left(\omega, p_{\omega}\right)$ where $p_{\omega}>p_{f}+[v(q+1)-v(q)]$, then there is a blocking set of the form $\left\{\left(\psi, p_{\omega}-[v(q+1)-v(q)]\right)\right\}$ where $b(\psi)=b(\omega), s(\psi)=s(\omega), q(\psi)=$ $q(\omega)+1$. If $p_{\omega}<p_{f}+[v(q+1)-v(q)]$, there will exist a blocking set of the form $\left\{\left(\psi, \frac{p_{\omega}+p^{\min }(q+1)}{2}\right)\right\}$, as we know at a price $p_{\omega}<p^{\min }(q+1)$ more buyers will demand to buy a good of quality $q+1$ then there are sellers willing to sell such a good.

(f) Finally, we prove that the number of trades is as given in the theorem. Suppose not. It is clear that if $m, m^{\prime} \in \mathcal{M}(q)$ and $m<\hat{m}<m^{\prime}$, then $\hat{m} \in \mathcal{M}(q)$. Hence, there are two cases to consider:

i. Suppose $|A|<m$ for all $m \in \mathcal{M}(q)$. Then there exists a buyer $b$ such that $f^{b}\left(\left|A_{b}\right|\right)+v(q)-p_{f}>0$. Furthermore, there exists a seller $s$ such that $p_{f}-\left[c^{s}\left(\left|A_{s}\right|\right)+e(q)\right]>0$ as we know from the definition of $p^{\max }(q)$ that the number of items of quality $q$ sellers are willing to sell at $p_{f}$ is strictly greater 
than the number of items buyers are willing to buy. Hence, a set $\left\{\left(\chi, p_{\chi}\right)\right\}$ such that $b(\chi)=b, s(\chi)=s, q(\chi)=q$, and $p_{\chi}=p_{f}$ constitutes a blocking set.

ii. Suppose $|A|>m$ for all $m \in \mathcal{M}(q)$. Then there exists a buyer $b$ such that $f^{b}\left(|A|_{b}\right)+v(q)-p_{f}<0$. Then the outcome is not individually rational for $b$. (Recall that the buyers are indifferent between the two qualities, given their prices, in the stable outcome $A$.)

3. $p^{\max }(q+1)-[v(q+1)-v(q)]<p_{f}<p^{\min }(q+1)$ : First, note that steps (a)-(d) of Case 2 still hold. We now show that no contract with a quality $q$ good transacts as part of a stable outcome. Suppose both qualities do trade in equilibrium. There are two cases

(a) Suppose

$$
p^{\max }(q+1)=\min _{b \in B}\left\{f^{b}\left(\left|\hat{A}_{b}\right|\right)-f^{b}\left(\left|\hat{A}_{b}\right|-1\right)+v(q+1)\right\} .
$$

Then since $p^{\max }(q+1)<p_{f}+[v(q+1)-v(q)]$, and all buyers recieve the same utility, there must be less than $m$ buyers, where $m=\min \mathcal{M}(q+1)$. However, sellers wish to sell at least $m$ goods of quality $q+1$ at that price. Hence there is a blocking contract where a seller who is not currently signing a contract offers a slightly lower price (and quality $q+1$ ) to a buyer currently buying.

(b) Suppose

$$
p^{\max }(q+1)=\min _{S \in S}\left\{c^{s}\left(\left|\hat{A}_{s}\right|\right)-c^{s}\left(\left|\hat{A}_{s}\right|-1\right)+e(q+1)\right\} .
$$

Then since $p^{\max }(q+1)<p_{f}+[v(q+1)-v(q)]$, and all buyers recieve the same utility, there are at most $m$ buyers, where $m=\max \mathcal{M}(q+1)$. However, sellers wish to sell at least $m+1$ goods of quality $q+1$ at that price. Hence there is a blocking contract where a seller who is not currently signing a contract offers a slightly lower price (and quality $q+1$ ) to a buyer currently buying.

The rest of the proof then follows as in the proof of Theorem 2. 


\section{A.5 Proof of Theorem 5}

The proof is symmetric to the proof of Theorem 4 . 


\section{B Instructions}

Introduction Welcome to the Laboratory for Experimental Economics and Political Science. This is an experiment in the economics of market decision making. The instructions are simple and if you follow them carefully and make good decisions you might earn money which will be paid to you in cash. We are going to conduct a market in which you will be a participant in a sequence of market days or trading periods. Attached to the instructions you will find a table labeled PAYOFF TABLE that describes the value to you of any decisions you might make. You are not to reveal this information to anyone. It is your own private information. The type of currency used in this market is francs. All trading and earnings will be in terms of francs. At the end of the experiment, your francs will be converted to dollars, and paid to you in cash. Your conversion rate is found on your table of values/costs. It may vary between people. Do not reveal this to anyone. The commodity being bought and sold comes in 10 different qualities, ranging from A to J. You will be designated as either a buyer or seller. If you are buyer your PAYOFF TABLE will be titled BUYER RECORD SHEET. If you are a seller, your PAYOFF TABLE will be labeled SELLER RECORD SHEET.

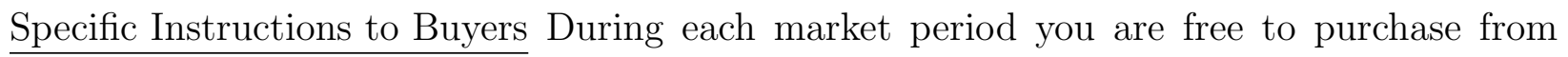
any seller or sellers as many units as you want. Each unit is one of ten different qualities, ranging from A to J. For the first unit that you buy during a trading period, you will receive the amount listed in the row marked "1st Unit Value" and the column corresponding to the quality of the item on your TABLE OF VALUES. If you purchase a second unit during that same period, you repeat the procedure, this time referring to the row marked "2nd Unit Value", and so on. Notice that your units increase regardless of the quality of the previous units purchased. That is, for the first unit you follow the first row, regardless of quality and for the second unit you follow the second row, regardless of the quality of the first unit. Similarly for the third unit you follow the third row regardless of the quality of the previous two unit. Your payoffs are computed as follows: you will receive the difference between the 
value on your table and what you paid for the purchase.

$$
\text { Earnings }=\text { Table Value }- \text { Purchase Price. }
$$

If the value of the item is greater than the purchase price you make money. If the value of the item is less than the purchase price, you lose money. Your total payoffs will be accumulated over several trading periods and the total amount will be paid to you after the experiment.

Specific Instructions to Sellers During each market period you are free to sell to any buyer or buyers as many units as you might want. Each unit is one of seven different qualities, ranging from $\mathrm{A}$ to $\mathrm{G}$. The cost of the first unit that you sell during a trading period is listed in the row marked "1st Unit Cost" and the column corresponding to the quality of the item on your TABLE OF COSTS. If you sell a second unit during that same period, you repeat the procedure, this time referring to the row marked "2nd Unit Cost", and so on. Your payoffs are computed as follows: you will receive the difference between the sale price of the unit and its cost on your table.

\section{Earnings $=$ Sale Price - Cost of Unit}

If the sale price of the item is greater than the cost you make money. If the sale price is less than the cost, you lose money. Your total payoffs will be accumulated over several trading periods and the total amount will be paid to you after the experiment.

Market Organization The exercise is organized as follows. The market will be conducted in a series of trading periods. Each period lasts for at most 15 minutes. Any buyer is free at any time during the period to make a verbal bid to buy a unit of a certain quality at a specified price. Likewise, any seller is free to make a verbal offer, or "ask", for one unit of a 
specified quality for a specified price. This is done by stating the quality, your ID number, and your bid or ask is (example: "quality F, Buyer 2 bids 40" or "quality D, Seller 5 asks 200".) Bids and asks are recorded on the blackboard by the market manager. Once a new bid or ask is announced, any new bid for that quality must be higher than the previous bid and any new ask for that quality must be lower than the previous ask. A unit is traded when a buyer accepts an existing ask (i.e. calling out "Buyer 2 accepts for quality A") or when a seller accepts an existing bid (i.e. calling out "Seller 6 accepts quality G"). When this happens, the buyer and the seller record the quality, price, and value or cost in the appropriate column of their Record sheet. Each column represents a trading period. Buyers and sellers can cancel their own asks or bids by calling out "Seller 7 cancels in quality B" or "Buyer 3 cancels in quality C". Except for the bids, asks, and cancellations, you are not allowed to speak. There are likely to be many bids and asks that are not accepted, but you are free to keep trying. You are free to make as much profit as you can. 


\section{Tables}

Table 1: Experiments and conditions

\begin{tabular}{|c|c|c|c|c|c|}
\hline Series & Experiment & Condition & \multicolumn{2}{|c|}{ Number of Subjects } & Number of Periods \\
\hline 1 & 1.1 & No price constraints & 8 sellers & 8 buyers & 7 \\
\hline 1 & 1.2 & No price constraints & 8 sellers & 7 buyers & 3 \\
\hline 1 & 1.3 & Price floor $(6,000)$ & 8 sellers & 7 buyers & 8 \\
\hline 1 & 1.4 & $\begin{array}{l}\text { First } 3 \text { periods: Price floor }(6,000) \\
\text { Last } 4 \text { periods: No price constraints }\end{array}$ & 8 sellers & 8 buyers & 7 \\
\hline 1 & 1.5 & $\begin{array}{l}\text { First } 6 \text { periods: Price floor }(6,000) \\
\text { Last } 2 \text { periods: No price constraints }\end{array}$ & 7 sellers & 7 buyers & 8 \\
\hline 2 & 2.1 & Price floor (1312) & 8 sellers & 8 buyers & 9 \\
\hline 2 & 2.2 & $\begin{array}{l}\text { First } 4 \text { periods: price floor }(1,470) \\
\text { Last } 3 \text { periods: No price constraints }\end{array}$ & 8 sellers & 8 buyers & 7 \\
\hline 2 & 2.3 & Price ceiling (1088) & 8 sellers & 8 buyers & 10 \\
\hline 2 & 2.4 & Price ceiling (930) & 7 sellers & 7 buyers & 10 \\
\hline
\end{tabular}


Table 2: Type 1 buyer's valuation and Type 1 seller's cost in Series 1

Type 1 buyer's valuation

\begin{tabular}{ccccccccccc}
\hline & & & \multicolumn{1}{c}{ Quality } & & & & \\
& $\mathrm{A}$ & $\mathrm{B}$ & $\mathrm{C}$ & $\mathrm{D}$ & $\mathrm{E}$ & $\mathrm{F}$ & $\mathrm{G}$ & $\mathrm{H}$ & $\mathrm{I}$ & $\mathrm{J}$ \\
\hline Unit & & & & & & & & & & \\
1 & 5988 & 6680 & 7238 & 7674 & 8000 & 8228 & 8370 & 8438 & 8444 & 8400 \\
2 & 5388 & 6080 & 6638 & 7074 & 7400 & 7628 & 7770 & 7838 & 7844 & 7800 \\
3 & 4788 & 5480 & 6038 & 6474 & 6800 & 7028 & 7170 & 7238 & 7244 & 7200 \\
4 & 4188 & 4880 & 5438 & 5874 & 6200 & 6428 & 6570 & 6638 & 6644 & 6600 \\
5 & 3588 & 4280 & 4838 & 5274 & 5600 & 5828 & 5970 & 6038 & 6044 & 6000 \\
6 & 2988 & 3680 & 4238 & 4674 & 5000 & 5228 & 5370 & 5438 & 5444 & 5400 \\
7 & 2388 & 3080 & 3638 & 4074 & 4400 & 4628 & 4770 & 4838 & 4844 & 4800 \\
8 & 1788 & 2480 & 3038 & 3474 & 3800 & 4028 & 4170 & 4238 & 4244 & 4200 \\
9 & 1188 & 1880 & 2438 & 2874 & 3200 & 3428 & 3570 & 3638 & 3644 & 3600 \\
10 & 588 & 1280 & 1838 & 2274 & 2600 & 2828 & 2970 & 3038 & 3044 & 3000 \\
\hline & & & & & & & & & & \\
& & & & Type 1 seller's cost & & & & \\
\hline & & & & & Quality & & & & & \\
& $\mathrm{A}$ & $\mathrm{B}$ & $\mathrm{C}$ & $\mathrm{D}$ & $\mathrm{E}$ & $\mathrm{F}$ & $\mathrm{G}$ & $\mathrm{H}$ & $\mathrm{I}$ & $\mathrm{J}$ \\
\hline Unit & & & & & & & & & & \\
1 & 3413 & 3690 & 4013 & 4377 & 4781 & 5220 & 5693 & 6195 & 6725 & 7278 \\
2 & 3433 & 3710 & 4033 & 4397 & 4801 & 5240 & 5713 & 6215 & 6745 & 7298 \\
3 & 3453 & 3730 & 4053 & 4417 & 4821 & 5260 & 5733 & 6235 & 6765 & 7318 \\
4 & 3473 & 3750 & 4073 & 4437 & 4841 & 5280 & 5753 & 6255 & 6785 & 7338 \\
5 & 3493 & 3770 & 4093 & 4457 & 4861 & 5300 & 5773 & 6275 & 6805 & 7358 \\
6 & 3513 & 3790 & 4113 & 4477 & 4881 & 5320 & 5793 & 6295 & 6825 & 7378 \\
7 & 3533 & 3810 & 4133 & 4497 & 4901 & 5340 & 5813 & 6315 & 6845 & 7398 \\
8 & 3553 & 3830 & 4153 & 4517 & 4921 & 5360 & 5833 & 6335 & 6865 & 7418 \\
9 & 3573 & 3850 & 4173 & 4537 & 4941 & 5380 & 5853 & 6355 & 6885 & 7438 \\
10 & 3593 & 3870 & 4193 & 4557 & 4961 & 5400 & 5873 & 6375 & 6905 & 7458 \\
\hline & & & & & & & & & &
\end{tabular}


Table 3: Type 1 buyer's valuation and Type 1 seller's cost in Series 2

\begin{tabular}{cccc}
\multicolumn{4}{c}{ Type 1 buyer's valuation } \\
\hline \multicolumn{4}{c}{ Quality } \\
& A & B & C \\
\hline Unit & & & \\
1 & 1555 & 2155 & 2355 \\
2 & 1375 & 1975 & 2175 \\
3 & 1195 & 1795 & 1995 \\
4 & 1015 & 1615 & 1815 \\
5 & 835 & 1435 & 1635 \\
6 & 655 & 1255 & 1455 \\
7 & 475 & 1075 & 1275 \\
8 & 295 & 895 & 1055 \\
9 & 115 & 715 & 915 \\
9 & -65 & 535 & 735 \\
\hline
\end{tabular}

\begin{tabular}{|c|c|c|c|}
\hline \multicolumn{4}{|c|}{$\frac{\text { Type } 1 \text { seller's }}{\text { Quality }}$} \\
\hline & A & B & $\mathrm{C}$ \\
\hline \multicolumn{4}{|c|}{ Unit } \\
\hline 1 & 45 & 245 & 845 \\
\hline 2 & 225 & 425 & 1025 \\
\hline 3 & 405 & 605 & 1205 \\
\hline 4 & 585 & 785 & 1385 \\
\hline 5 & 765 & 965 & 1565 \\
\hline 6 & 945 & 1145 & 1745 \\
\hline 7 & 1125 & 1325 & 1925 \\
\hline 8 & 1305 & 1505 & 2105 \\
\hline 9 & 1485 & 1685 & 2285 \\
\hline 10 & 1665 & 1865 & 2465 \\
\hline
\end{tabular}


Table 4: Efficiency and number of units traded by period for Series 1

\begin{tabular}{|c|c|c|c|c|c|c|c|}
\hline \multirow[t]{2}{*}{ Experiment } & \multirow{2}{*}{$\begin{array}{c}1.1 \\
\text { No } \\
\text { price } \\
\text { floor }\end{array}$} & \multirow{2}{*}{$\begin{array}{l}1.2 \\
\text { No } \\
\text { price } \\
\text { floor }\end{array}$} & \multirow{2}{*}{$\begin{array}{c}1.3 \\
\text { With } \\
\text { price } \\
\text { floor }\end{array}$} & \multicolumn{2}{|c|}{1.4} & \multicolumn{2}{|c|}{1.5} \\
\hline & & & & $\begin{array}{l}\text { With } \\
\text { price } \\
\text { floor }\end{array}$ & $\begin{array}{c}\text { No } \\
\text { price } \\
\text { control }\end{array}$ & $\begin{array}{l}\text { With } \\
\text { price } \\
\text { floor }\end{array}$ & $\begin{array}{c}\text { No } \\
\text { price } \\
\text { control }\end{array}$ \\
\hline Period & & & & & & & \\
\hline 1 & 0.823 & 0.815 & 0.597 & 0.667 & & 0.646 & \\
\hline 2 & 0.859 & 0.875 & 0.609 & 0.643 & & 0.651 & \\
\hline 3 & 0.913 & 0.952 & 0.532 & 0.641 & & 0.628 & \\
\hline 4 & 0.918 & & 0.609 & & 0.789 & 0.629 & \\
\hline 5 & 0.934 & & 0.591 & & 0.953 & 0.649 & \\
\hline 6 & 0.926 & & 0.604 & & 0.961 & 0.632 & \\
\hline 7 & 0.936 & & 0.641 & & 0.988 & & 0.879 \\
\hline 8 & & & 0.649 & & & & 0.935 \\
\hline Mean efficiency & 0.901 & 0.881 & 0.604 & 0.650 & 0.923 & 0.639 & 0.907 \\
\hline $\begin{array}{l}\text { Efficiency } \\
\text { in a stable outcome } \\
\text { (Theoretical prediction) }^{1}\end{array}$ & 1.000 & 1.000 & 0.661 & 0.660 & 1.000 & 0.662 & 1.000 \\
\hline $\begin{array}{l}\text { Average number of } \\
\text { units traded per period }\end{array}$ & 43.1 & 44.3 & 27.8 & 32.3 & 43.3 & 31.5 & 36.5 \\
\hline $\begin{array}{l}\text { Number of trades } \\
\text { in a stable outcome } \\
\text { (Theoretical prediction) }^{1}\end{array}$ & 44 & 39 & 28 & 32 & 44 & 28 & 39 \\
\hline
\end{tabular}

Table 5: Proportion of trade by quality during the second half periods in Series 1 (percent)

\begin{tabular}{|c|c|c|c|c|c|c|c|c|c|c|}
\hline Experimental Treatments & $\mathrm{A}$ & $\mathrm{B}$ & $\mathrm{C}$ & $\mathrm{D}$ & $\mathrm{E}$ & $\mathrm{F}$ & G & $\mathrm{H}$ & $\mathrm{I}$ & $\mathrm{J}$ \\
\hline $\begin{array}{l}\text { No price floor } \\
\quad \text { (Periods } 5-7, \text { Experiment } 1.1 \text { ) }\end{array}$ & 7.6 & 4.6 & 12.1 & 62.1 & 12.1 & 1.5 & 0.0 & 0.0 & 0.0 & 0.0 \\
\hline $\begin{array}{l}\text { With price floor } \\
\text { (Periods } 5-8, \text { Experiment } 1.3 \\
\text { \& Periods } 5-6, \text { Experiment } 1.5 \text { ) }\end{array}$ & 0.0 & 0.0 & 0.0 & 0.0 & 0.0 & 0.5 & 83.6 & 14.9 & 0.5 & 0.5 \\
\hline
\end{tabular}


Table 6: Coefficient estimates

\begin{tabular}{lrrrrrrr}
\hline & $\beta_{1}$ & $\beta_{2}$ & $\beta_{3}$ & $\beta_{4}$ & $\gamma$ & $n$ & $R^{2}$ \\
\hline Series 1 & 264.9 & -210.7 & & 23.5 & 36.0 & 20 & 0.739 \\
& $(44.8)^{1}$ & $(96.2)$ & & $(43.0)$ & $(20.8)$ & & \\
\hline Series 2 & 30.0 & & -51.0 & & 6.7 & 19 & 0.625 \\
& $(15.7)$ & & $(16.3)$ & & $(3.5)$ & & \\
\hline Series 2 & & -16.3 & & -5.9 & -8.3 & 17 & 0.671 \\
& & $(1.8)$ & & $(4.1)$ & $(3.2)$ & & \\
\hline
\end{tabular}

${ }^{1}$ Standard errors are in parentheses.

Table 7: Efficiency and number of units traded by period for Series 2

\begin{tabular}{|c|c|c|c|c|c|}
\hline \multirow[t]{2}{*}{ Experiment } & \multirow{2}{*}{$\begin{array}{c}2.1 \\
\text { Price floor } \\
1312\end{array}$} & \multicolumn{2}{|c|}{2.2} & \multirow{2}{*}{$\begin{array}{c}2.3 \\
\text { Price ceiling } \\
1088\end{array}$} & \multirow{2}{*}{$\begin{array}{c}2.4 \\
\text { Price ceiling } \\
930\end{array}$} \\
\hline & & $\begin{array}{c}\text { Price floor } \\
1470\end{array}$ & $\begin{array}{c}\text { No price } \\
\text { control }\end{array}$ & & \\
\hline \multicolumn{6}{|l|}{ Period } \\
\hline 1 & 0.711 & 0.690 & & 0.861 & 0.809 \\
\hline 2 & 0.835 & 0.707 & & 0.922 & 0.750 \\
\hline 3 & 0.814 & 0.683 & & 0.699 & 0.683 \\
\hline 4 & 0.777 & 0.693 & & 0.548 & 0.608 \\
\hline 5 & 0.708 & & 1.000 & 0.856 & 0.677 \\
\hline 6 & 0.772 & & 1.000 & 0.851 & 0.676 \\
\hline 7 & 0.778 & & 1.000 & 0.885 & 0.677 \\
\hline 8 & 0.736 & & & 0.873 & 0.665 \\
\hline 9 & 0.754 & & & 0.910 & 0.657 \\
\hline 10 & & & & 0.882 & 0.693 \\
\hline Mean efficiency & 0.765 & 0.693 & 1.000 & 0.829 & 0.690 \\
\hline $\begin{array}{c}\text { Efficiency } \\
\text { in a stable outcome } \\
\text { (Theoretical prediction) }\end{array}$ & $0.664-0.984$ & 0.633 & 1.000 & $0.664-0.984$ & 0.635 \\
\hline $\begin{array}{c}\text { Average number of } \\
\text { units traded per period }\end{array}$ & 41.4 & 35.5 & 43.6 & 48.0 & 31.8 \\
\hline $\begin{array}{l}\text { Number of trades } \\
\text { in a stable outcome } \\
\text { (Theoretical prediction) }\end{array}$ & 38 & 34 & 44 & 38 & 30 \\
\hline
\end{tabular}


Table 8: Proportion of trade by quality during the second half periods in Series 2 (percent)

\begin{tabular}{llccc}
\hline \multicolumn{2}{c}{ Experimental Treatments } & A & B & C \\
\hline Price floor 1312 & (Experiment 2.1) & 1.6 & 49.4 & 49.0 \\
Price floor 1470 & (Periods 1-4, Experiment 2.2) & 1.4 & 5.5 & 93.1 \\
No price control & (Periods 5-7, Experiment 2.2) & 2.8 & 93.1 & 4.1 \\
Price ceiling 1088 & (Experiment 2.3) & 26.0 & 72.2 & 1.8 \\
Price ceiling 930 & (Experiment 2.4) & 97.5 & 2.5 & 0.0 \\
\hline
\end{tabular}

